\title{
RMetS
}

\section{A large-eddy model for cirrus clouds with explicit aerosol and ice microphysics and Lagrangian ice particle tracking}

\author{
Ingo Sölch*and Bernd Kärcher \\ Deutsches Zentrum für Luft- und Raumfahrt, Institut für Physik der Atmosphäre, Oberpfaffenhofen, Germany \\ ${ }^{\star}$ Correspondence to: I. Sölch, DLR, Oberpfaffenhofen, Wessling 82230, Germany. E-mail: ingo.soelch@dlr.de
}

\begin{abstract}
We introduce a novel large-eddy model for cirrus clouds with explicit aerosol and ice microphysics, and validate its central components. A combined Eulerian/Lagrangian approach is used to simulate the formation and evolution of cirrus. While gas and size-resolved aerosol phases are treated over a fixed Eulerian grid similar to the dynamical and thermodynamical variables, the ice phase is treated by tracking a large number of simulation ice particles. The macroscopic properties of the ice phase are deduced from statistically analysing large samples of simulation ice particle properties. The new model system covers non-equilibrium growth of liquid supercooled aerosol particles, their homogeneous freezing, heterogeneous ice nucleation in the deposition or immersion mode, growth of ice crystals by deposition of water vapour, sublimation of ice crystals and their gravitational sedimentation, aggregation between ice crystals due to differential sedimentation, the effect of turbulent dispersion on ice particle trajectories, diabatic latent and radiative heating or cooling, and radiative heating or cooling of ice crystals. This suite of explicitly resolved physical processes enables the detailed simulation and analysis of the dynamical-microphysical-radiative feedbacks characteristic of cirrus.

We draw special attention to the ice aggregation process which redistributes large ice crystals vertically and changes the ice particle size distributions accordingly. We find that aggregation of ice crystals is the key process to generate precipitation-sized ice crystals in stratiform cirrus. A process-oriented algorithm is developed for ice aggregation based on the trajectories and sedimentation velocities of simulation ice particles for use in the dynamically and microphysically complex, multi-dimensional large-eddy approach. By virtue of an idealized model set-up, designed to isolate the effect of aggregation on the cirrus development, we show that aggregation and its effect on the ice crystal size distribution in the model is consistent with a theoretical scaling relation, which was found to be in good agreement with in situ measurements. Copyright (C) 2010 Royal Meteorological Society
\end{abstract}

\footnotetext{
Key Words: cloud-resolving models; large-eddy simulations; ice aggregation

Received 22 April 2010; Revised 22 July 2010; Accepted 23 July 2010; Published online in Wiley Online Library 28 September 2010
}

Citation: Sölch I, Kärcher B. 2010. A large-eddy model for cirrus clouds with explicit aerosol and ice microphysics and Lagrangian ice particle tracking. Q. J. R. Meteorol. Soc. 136: 2074-2093. DOI:10.1002/qj.689

1. Introduction

Cirrus clouds predominantly inhabit the global upper troposphere and tropopause region and are exclusively composed of ice crystals comprising a wide array of sizes and habits (shapes). They contribute to global warming by acting primarily as greenhouse agents because they are strong absorbers of radiation in the infrared spectral region (Liou, 
1986; Chen, et al., 2000; Lynch, et al., 2002). Past research on cirrus clouds revealed their multiscale nature and a number of cloud-controlling factors including mesoscale temperature fluctuations, competition of various aerosol particle types during ice formation, and stabilization through infrared differential heating (Kärcher and Spichtinger, 2009). Therefore, to predict cirrus cloud formation and evolution, it is necessary to understand the interplay between dynamical, microphysical, and radiative processes, both at the scale of the cloud and in concert with the synoptic-scale flow.

The ice phase in cirrus differs from the liquid (warm cloud) phase in at least two fundamental aspects: (i) there exists a substantial supersaturation barrier to ice nucleation (tens of percent), causing the widespread existence of clearsky ice supersaturated areas in the upper troposphere (Koop, et al., 2000; Kahn, et al., 2009); and (ii) low temperatures cause long sub- and supersaturation relaxation time-scales (tens of minutes or longer), implying that large regions within cirrus frequently exist in thermodynamic nonequilibrium conditions (Ovarlez, et al., 2002; Jensen and Pfister, 2005; Kärcher, 2005). These aspects have important consequences for parametrizing cirrus fractional coverage and ice microphysics in general circulation models, as conventional cloud parametrizations relying on saturation adjustment and diagnostic cloud coverages cannot be adopted for cirrus in a physically consistent manner (Kärcher and Burkhardt, 2008).

Airborne microphysical measurements of cirrus are challenging owing to the inaccessibility at high altitudes, espcially in the Tropics, as well as instrumental issues tied to the detection of small (micrometre-sized) ice crystals and the quantification of their number, effective size, and habit (Lawson, et al., 2006; Heymsfield, 2007; Stoelinga, et al., 2007; Jensen, et al., 2009). The semi-transparent nature of most large-scale cirrus, exhibiting mean solar optical depths below unity, renders passive remote sensing methods uncertain (Comstock, et al., 2007; Kärcher, et al., 2009b) and leads to widely varying quantitative results concerning cirrus occurrence frequencies or cloud amount and cirrus properties, depending on the type of observation (nadir or limb) and underlying retrieval method (Stephens and Kummerow, 2007; Bankert, et al., 2009).

Substantial progress in understanding cirrus clouds and their global climate impact may not be possible without detailed process-based numerical simulations, because many cirrus-related phenomena involve a complex interplay of physical processes acting on a wide range of spatial and temporal scales (Kärcher and Spichtinger, 2009). Furthermore, it is conceivable that the importance of cirrus cloud-resolving simulations will continue to grow due to measurement limitations, and so there is a need to develop new approaches for parametrizing cirrus in large-scale models.

The use of bulk microphysical schemes in cirrus models has a long tradition. Most existing schemes predict ice cloud mass and are therefore computationally efficient enough for use in a multi-dimensional framework such as large-eddy simulations (LESs) (Starr and Cox, 1985; Shutts and Gray, 1994; Gu and Liou, 2000). More recently, two-moment schemes based on ice water content and total ice crystal number density have been developed and are being used in LESs or mesoscale models (Levkov et al., 1992; Seifert and Beheng, 2006; Morrison and Grabowski, 2008;

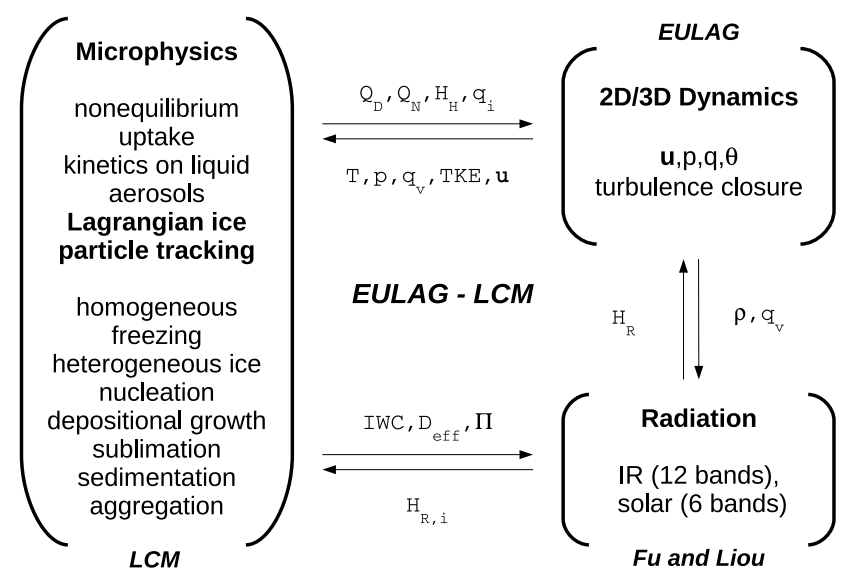

Figure 1. Schematic overview of the DLR EULAG-LCM model system. The LCM (Lagrangian Cirrus Module) can also be coupled to other dynamical core and radiation models, provided the interfaces for the exchange of model variables are similar.

Spichtinger and Gierens, 2009). These one- or two-moment bulk schemes are valuable in conducting many sensitivity studies involving a large number of parameters. In these schemes, however, microphysical and radiative processes are heavily parametrized, which limits their usefulness to study in detail the effects of individual processes on the evolution of clouds. To arrive at more realistic simulations that enable a better control of underlying processes, some cloud models employ size-resolved ice microphysics (bin schemes) to directly predict the ice particle size distribution (PSD) (Jensen, et al., 1994; Khvorostyanov and Sassen, 1998; Monier, et al., 2006). A notorious problem in the traditional bin schemes is the artificial numerical diffusion connected with ice crystal sedimentation and ice mass growth by water vapour deposition. With few exceptions, cirrus formation from ice-nucleating aerosol particles is only very crudely described in all of the above models.

The aim of the present study is to introduce and validate a novel LES model system for cirrus, the EULAG-LCM (Figure 1). This model system is based on a non-hydrostatic, anelastic numerical solver for geophysical flows, the EULAG (Grabowski and Smolarkiewicz, 2002), using a subgridscale turbulence parametrization (Schumann, 1991) with the premise that we resolve the dominant turbulent scales in our simulations. We have coupled the EULAG to a well-established radiative transfer scheme based on the $\delta$-four-stream approximation (Liou, et al., 1988) and to a newly developed cloud package that treats nonequilibrium aerosol and ice microphysics in great detail, the Lagrangian Cirrus Module (LCM). In a similar fashion to the fluid variables (mass density of air, momentum, pressure, potential temperature), water vapour, and potentially other trace gases, the size-resolved aerosol particles consisting of liquid supercooled solution droplets and bare or coated insoluble heterogeneous ice nuclei (IN), are treated over a fixed Eulerian grid. Concerning the ice phase, the LCM employs Lagrangian ice particle tracking (LPT), in which a large number of simulation ice particles (SIPs), serving as surrogates of real ice crystals, are transported and modified in the turbulent flow field. For typical upper-tropospheric temperatures $(220 \mathrm{~K})$, pressures $(300 \mathrm{hPa})$, and ice crystal number concentrations $\left(<1 \mathrm{~cm}^{-3}\right)$, at most one ice crystal resides in an air volume of $1 \mathrm{~cm}^{3}$, compared to $\sim 10^{19}$ air molecules and $\sim 10^{14}-10^{15}$ water molecules. Therefore, 
treating the air as a continuum and the ice phase as dispersed particles appears to be well suited for cirrus cloud simulations.

At first glance, the way the ice phase is treated in the turbulent cloud dynamical environment in the LCM shows similarities to approaches created to study warm clouds, in particular cumulus clouds (Stevens, et al., 1996; LasherTrapp, et al., 2005). In the trajectory ensemble approach used in these studies, a large number of trajectories taken from LES with a simple representation of the moisture and condensate fields is used off-line (a posteriori) to drive parcel models containing a detailed microphysical description of the processes affecting cloud droplet size and composition. The droplet trajectories include turbulent components and are used to derive statistical information regarding droplet ensembles. This approach enabled deeper insights into the role of entrainment and mixing, as well as the causes of the broadening of the cumulus droplet size distributions.

By contrast, cirrus clouds exhibit specific features that render such an off-line approach difficult, among which are the paramount role of sedimentation in determining the cloud structure and radiative response, and the absence of a critical threshold for the onset and development of precipitation. Consequently, in the LCM, the SIPs are included in the actual simulations, and, therefore, feed back interactively on the formation and evolution of cirrus.

In our model, individual SIPs can be associated either with static flags memorizing, e.g. the chemical nature of the ice-nucleating precursor particles or changes in ice crystal habit, or with time-dependent variables recording, e.g. the particle's spatial locations or supersaturation history. The LPT also allows ice crystal properties or the processes affecting ice crystals to be studied in great detail in a statistical manner. Therefore, the LPT provides unprecedented analysis tools to describe the evolution of the ice phase and to compare such simulations with in situ measurements. One particularly important process investigated in the present work and in Sölch and Kärcher (2010) is ice aggregation, whereby individual ice crystals collide and eventually stick together, forming particles of larger sizes and more complex shapes. Finally, LPT avoids artifical numerical diffusion. We believe that these advantages outweigh by far the substantial demand of computational resources required by LPT, a problem that will diminish over time as more powerful computers become available.

Section 2 introduces the core model components and discusses all salient features of the representation of SIP, including the LPT. Section 3 is devoted to the validation of the ice nucleation and growth processes as treated in the LCM. Section 4 presents a new algorithm describing ice aggregation by clustering of individual SIPs. The clustering is induced by differential sedimentation of ice particles with different terminal fall speeds. Section 5 validates the aggregation process and its effect on the PSD as represented in the EULAG-LCM by means of an idealised case-study that leads to a universal self-similar PSD scaling law. Section 6 concludes the paper and provides a brief outlook. The appendix lists details of the treatment of ice microphysical processes.

\section{The EULAG-LCM model system}

As displayed in Figure 1, the LCM treats a number of aerosol and ice-related processes and their corresponding interactions without imposing thermodynamic equilibrium assumptions. The figure also lists the variables exchanged between the three different core components. (Symbols and abbreviations are summarized in Table AI.)

The prognostic equations used in the dynamical core, aerosol growth and evaporation rates, freezing and ice nucleation processes, microphysics of ice crystals and their representation as simulation ice particles, radiative transfer, radiative effects on ice crystal growth and sublimation, and several numerical details are discussed in this section. Supplementary information concerning ice microphysical properties, such as habit-dependent capacitances and terminal fall velocities, as well as gas kinetic correction, and ventilation factors affecting the diffusional growth law are summarized in the appendix.

\subsection{Dynamical core}

The dynamical core of our model system is the anelastic nonhydrostatic fluid model EULAG. The governing equations for moist adiabatic motion are written as:

$$
\begin{aligned}
\frac{\mathrm{d} \mathbf{u}}{\mathrm{d} t}+f \mathbf{k} \times \mathbf{u}^{\prime} & =-\nabla\left(\frac{p^{\prime}}{\bar{\rho}}\right)+\mathbf{g}\left(\frac{\theta_{\mathrm{d}}^{\prime}}{\bar{\theta}}\right)+\mathbf{D}_{\mathbf{u}}, \\
\nabla \cdot(\bar{\rho} \mathbf{u}) & =0, \\
\frac{\mathrm{d} \theta^{\prime}}{\mathrm{d} t} & =-\mathbf{u} \cdot \nabla \theta_{\mathrm{e}}+\mathbf{D}_{\theta}+H_{\mathrm{R}}+H_{\mathrm{H}}, \\
\frac{\mathrm{d} q_{\mathrm{v}}}{\mathrm{d} t} & =\mathbf{D}_{q_{\mathrm{v}}}-Q_{\mathrm{N}}-Q_{\mathrm{D}} .
\end{aligned}
$$

The variables $\bar{\theta}$ and $\bar{\rho}$ denote the base state profiles for potential temperature and density, the subscript e referring to environmental profiles. Those environmental states may be inhomogeneous. Deviations from environmental profiles are indicated with primes in Eqs (1)-(3), e.g. $\theta^{\prime}=\theta-\theta_{\mathrm{e}}$. The vector $\mathbf{D}$ represents viscous forces for the corresponding variables, calculated using a prognostic equation for the turbulent kinetic energy. The parametrization of Schumann (1991) is used as a subgrid model for the decay and dissipation of unresolved turbulent eddies. In this context, we recall that the typical buoyancy and Ozmidov lengthscales in cirrus are of the order of several metres, according to aircraft measurements performed in stably stratified conditions (Quante and Starr, 2002). In the thermodynamic equation, $H_{\mathrm{R}}$ and $H_{\mathrm{H}}$ are heating rates due to radiation and latent heat from water vapour deposition or sublimation, respectively. $Q_{\mathrm{N}}$ and $Q_{\mathrm{D}}$ are the sink terms due to formation and depositional growth of ice crystals and the interaction of water vapour with liquid aerosol particles, respectively.

The coupling between ice and the flow field is expressed in Eq. (1) by $\theta_{\mathrm{d}}$ in the buoyancy term (Emanuel, 1994):

$$
\theta_{\mathrm{d}}=\theta+\bar{\theta}\left(\epsilon q_{\mathrm{v}}-q_{\mathrm{i}}\right),
$$

where $\epsilon=\left(R_{\mathrm{v}} / R_{\mathrm{d}}\right)-1$, and $q_{\mathrm{i}}$ is the total ice mass mixing ratio. Advection is solved using the implicit, positive definite algorithm MPDATA. We refer to Smolarkiewicz and Margolin (1998), and Grabowski and Smolarkiewicz (2002) for a more detailed description and validation of the dynamical equations and their numerical solution method. Since the ice phase constitutes only a small fraction $\left(\mathcal{O}\left(10^{-4}\right)\right.$ or less) of the total mass in a volume of air in cirrus clouds, the influence of ice particles on the air motion in cirrus is neglected. 
We solve Eqs (1)-(4) employing a Cartesian grid with constant grid spacings $\Delta x, \Delta y$, and $\Delta z$. The latter are chosen small enough $(\mathcal{O}(10 \mathrm{~m}))$ so that the large eddies in the energy production region are resolved in our simulations. Since microphysical processes are very sensitive to rapid humidity or temperature changes, the dynamical time step $\Delta t$ may be subcycled (divided into smaller steps) for growth processes $\left(\Delta t_{\mathrm{M}}\right)$ or during ice formation events $\left(\Delta t_{\mathrm{N}}\right)$, with $\Delta t_{\mathrm{N}} \leq \Delta t_{\mathrm{M}} \leq \Delta t$

\subsection{Aerosols}

Liquid solution droplets and/or insoluble heterogeneous IN are treated explicitly as the precursors of ice crystals in the LCM. This allows us to accurately simulate ice initiation in cirrus, including the competition between different ice formation pathways for the available water vapour (DeMott, et al., 1997). Processes considered are the non-equilibrium uptake of water vapour $\left(\mathrm{H}_{2} \mathrm{O}\right)$ and nitric acid $\left(\mathrm{HNO}_{3}\right)$ in liquid aerosol particles containing sulphuric acid $\left(\mathrm{H}_{2} \mathrm{SO}_{4}\right)$, homogeneous freezing, and heterogeneous ice nucleation in the immersion and deposition mode. We do not account for nucleation and coagulation of aerosol particles. Aerosol nucleation produces particles in the ultrafine size region $(<10 \mathrm{~nm}$ ) (Schröder, et al., 2002) and therefore does not directly affect cirrus formation. The Brownian coagulation time-scale (Pruppacher and Klett, 1997) between uppertropospheric aerosol particles is much longer than the period of a cirrus cloud simulation.

\subsubsection{Liquid aerosol particles}

The treatment of liquid aerosol particles is adopted from the Advanced Particle Simulation Code (APSCm; Kärcher, 2003), which has been used to interpret in situ and laboratory measurements and has been employed in a cirrus parcel model intercomparison exercise (Lin, et al., 2002). The droplets are composed of $\mathrm{H}_{2} \mathrm{SO}_{4}$ and $\mathrm{H}_{2} \mathrm{O}$, and may also dissolve $\mathrm{HNO}_{3}$. Sulphuric acid is a main constituent of aqueous particles in the upper troposphere (Murphy, et al., 1998; Finlayson-Pitts and Pitts, 2000). The homogeneous freezing properties of many supercooled aqueous solutions including $\mathrm{H}_{2} \mathrm{SO}_{4} / \mathrm{H}_{2} \mathrm{O}$ are well established (Koop, et al., 2000; Richardson, et al., 2010). Organic species may alter the freezing behaviour in external mixtures of chemically variable aerosols (Cziczo, et al., 2004; Kärcher and Koop, 2005; Murray, et al., 2010) and may be included in the LCM for specific applications.

To simulate chemical composition changes and sizedependent freezing probabilities of the spherical droplets, their size distribution is discretised over the radial coordinate, $r_{\mathrm{a}}$. We use the moving-centre size grid (Jacobson, 1999) to represent the discretised particle properties, in which the edges of a given size bin, $l$, are fixed but the aerosol particles are allowed to attain their exact radii, $r_{\mathrm{a}, l}$, in a certain bin during growth, largely eliminating numerical diffusion in radius space.

\subsubsection{Dissolution and growth}

Growth rates and chemical composition changes of aerosol particles by water vapour (or other trace gas) adsorption on the surface and subsequent dissolution into the liquid are solved via the set of dissolution equations for each size bin $l$,

$$
\frac{\mathrm{d} n_{\mathrm{v}, \mathrm{a}, l}}{\mathrm{~d} t}=\frac{4 \pi D_{\mathrm{v}} \beta_{\mathrm{v}, \mathrm{a}, l} r_{\mathrm{a}, l} n_{\mathrm{a}, l}}{k_{\mathrm{B}} T}\left(p_{\mathrm{v}}-p_{\mathrm{a}, \mathrm{s}, l}^{\prime}\right),
$$

where $n_{\mathrm{v}, \mathrm{a}, l}$ is the number concentration of $\mathrm{H}_{2} \mathrm{O}$ molecules residing in liquid aerosol particles of radius $r_{\mathrm{a}, l}$ and number concentration $n_{\mathrm{a}, l}, D_{\mathrm{v}}$ is the diffusion coefficient for $\mathrm{H}_{2} \mathrm{O}$ molecules in air (Appendix 6), $\beta_{\mathrm{v}, \mathrm{a}, l}$ is a size-dependent correction factor interpolating between diffusion-limited and free molecular growth regimes (analogous to the correction for ice crystals given in Appendix 6), $p_{\mathrm{v}}$ is the $\mathrm{H}_{2} \mathrm{O}$ gas phase partial pressure, $p_{\mathrm{a}, \mathrm{s}, l}^{\prime}$ is the equilibrium pressure of $\mathrm{H}_{2} \mathrm{O}$ over the solution droplet (Luo, et al., 1995) including a Kelvin correction for small droplets (Kärcher, 2003), and $k_{\mathrm{B}}$ is the Boltzmann constant. Equation (6) is coupled to the gas phase and the resulting set of equations is solved using the analytic predictor of dissolution scheme (Jacobson, 1999).

Should the relative humidity approach or surpass water saturation, e.g. in the presence of large cooling rates and/or at high temperatures, we allow for activation of the liquid aerosol droplets into nearly pure cloud water droplets that may subsequently grow by condensation of $\mathrm{H}_{2} \mathrm{O}$ and freeze homogeneously. As an option, $\mathrm{HNO}_{3}$ may dissolve in the solution droplet, forming ternary aerosol particles and enhancing the dissolution of $\mathrm{H}_{2} \mathrm{O}$ prior to droplet activation. This process affects the freezing history and may be relevant at the cold tropopause and in ice-supersaturated and $\mathrm{HNO}_{3}-$ rich conditions, when the abundance and solubility of $\mathrm{HNO}_{3}$ in diluted aqueous $\mathrm{H}_{2} \mathrm{SO}_{4}$ solutions become large (Kärcher and Solomon, 1999). In that case, a set of equations similar to Eq. (6) is solved tracking the $\mathrm{HNO}_{3}$ mass per liquid particle or droplet in each size class.

The time-scale of chemical production of $\mathrm{H}_{2} \mathrm{SO}_{4}$ from the $\mathrm{OH}$-induced oxidation of its most important uppertropospheric precursor $\mathrm{SO}_{2}$ is of the order of 1-2 weeks, much longer than typical cirrus cloud lifetimes, and is therefore not considered here. Therefore, we keep the $\mathrm{H}_{2} \mathrm{SO}_{4}$ mass per aerosol droplet constant during a cloud simulation; it would be straightforward to add the corresponding growth equations for $\mathrm{H}_{2} \mathrm{SO}_{4}$ vapour, analogous to Eq. (6), if necessary.

\subsubsection{Homogeneous freezing}

Homogeneous freezing rate coefficients, $J_{\mathrm{f}}$ (number of ice nucleation events per unit droplet volume and time), of supercooled aqueous solution droplets are obtained from the activity-based parametrization presented by Koop, et al. (2000). In this approach, $J_{\mathrm{f}}$ is an extremely sensitive function of $T$ and the size-dependent water activity, $a_{\mathrm{w}, l}$. The latter is defined as the ratio of the equilibrium vapour pressure of $\mathrm{H}_{2} \mathrm{O}$ over the solution droplet and the equilibrium vapour pressure, $p_{s}$, over a flat, pure water surface (Luo, et al., 1995). No equilibrium conditions are invoked. As a result, $a_{\mathrm{w}, l}$ depends on the temperature and on the actual $\mathrm{H}_{2} \mathrm{O}$ particle mass fraction and is not necessarily equal to the ambient relative humidity:

$$
a_{\mathrm{w}, l}=\frac{p_{\mathrm{a}, \mathrm{s}, l}^{\prime}}{p_{\mathrm{s}}} .
$$

The use of the non-equilibrium water activity is important in situations of large local cooling rates $\left(\mathcal{O}\left(1 \mathrm{~m} \mathrm{~s}^{-1}\right)\right)$ 
at low temperatures $(<210 \mathrm{~K})$. In such cases, large aerosol particles cannot equilibrate with the ambient water vapour on the time-scale over which the ambient relative humidity rises, which delays their freezing (Haag, et al., 2003a). Homogeneous freezing in liquid aerosol droplets in equilibrium with ambient water vapour commences at critical RHI thresholds in the range $150-170 \%$ for $T>195 \mathrm{~K}$ (Koop, et al., 2000; Möhler, et al., 2003), depending on the droplet volume.

The following set of coupled equations is solved for each size bin $l$ to simulate the phase transition (supercooled liquid to ice):

$$
\frac{\mathrm{d} n_{\mathrm{a}, l}}{\mathrm{~d} t}=-j_{\mathrm{f}} n_{\mathrm{a}, l}, \quad \frac{\mathrm{d} n_{\mathrm{i}}}{\mathrm{d} t}=j_{\mathrm{f}} n_{\mathrm{a}, l}
$$

where $n_{\mathrm{i}}$ is the number concentration of ice crystals and $j_{\mathrm{f}}=(4 / 3) \pi r_{\mathrm{a}, l}^{3} J_{\mathrm{f}}$ is the homogeneous freezing rate (number of ice nucleation events per aerosol particle and unit time). Local redistribution of water during freezing events is governed by the coupled system of equations

$$
\begin{aligned}
\frac{\mathrm{d} n_{\mathrm{v}, \mathrm{a}, l}}{\mathrm{~d} t} & =-j_{\mathrm{f}} n_{\mathrm{v}, \mathrm{a}, l}, \\
\frac{\mathrm{d} n_{\mathrm{v}, \mathrm{i}}}{\mathrm{d} t} & =j_{\mathrm{f}} n_{\mathrm{v}, \mathrm{a}, l}, \\
\frac{\mathrm{d} n_{\mathrm{v}}}{\mathrm{d} t} & =\sum_{l} j_{\mathrm{f}} n_{\mathrm{v}, \mathrm{a}, l} .
\end{aligned}
$$

\subsubsection{Heterogeneous ice nucleation}

Field and modelling studies suggest that besides homogeneous freezing of solution droplets, heterogeneous ice nucleation on insoluble aerosol particles may occur in the upper troposphere (DeMott, et al., 2003; Haag, et al., 2003b), and should therefore be considered in detailed cirrus cloud studies. In the LCM, heterogeneous nucleation is included via the immersion and deposition mode. Other modes of ice nucleation exist (condensation and contact mode), but those require the presence of water supersaturation and supercooled water droplets and are therefore not primarily relevant for cirrus studies.

The shifted activity method (Kärcher and Lohmann, 2003) is used to calculate heterogeneous ice nucleation rates in the immersion mode, retaining the activity-based formulation:

$$
j_{\mathrm{f}}=\underbrace{4 \pi r_{\mathrm{c}}^{2} \Delta J_{\mathrm{f}}\left(a_{\mathrm{w}, l}+\Delta a_{\mathrm{w}}\right)}_{\text {insoluble IN core surface }}+\underbrace{(4 / 3) \pi\left(r_{\mathrm{a}, l}^{3}-r_{\mathrm{c}}^{3}\right) J_{\mathrm{f}}\left(a_{\mathrm{w}, l}\right)}_{\text {liquid shell volume }} .
$$

The water activity shift $\Delta a_{\mathrm{w}}$ is prescribed such that nucleation occurs in a narrow range of the ice saturation ratio $( \pm 0.05$, similar to homogeneous freezing) around the desired critical threshold value $S_{\mathrm{cr}}$. The constant $\Delta=30 \mathrm{~nm}$ accounts for differences in the kinetic prefactors of the homogeneous and heterogeneous rate coefficients. Immersion mode nucleation requires a supercooled liquid aerosol particle containing an insoluble IN core (radius $r_{\mathrm{c}}$ ). The IN core is surrounded by a sufficiently thick liquid coating, the total (wet) IN radius being $r_{\mathrm{a}, l}>r_{\mathrm{c}}$. The first term in Eq. (12) describes the action of the IN core surface and the second term accounts for volume-controlled homogeneous freezing of the liquid shell. Unless $S_{\mathrm{cr}}$ is very close to the homogeneous freezing threshold and $r_{\mathrm{c}}$ is not too small relative to $r_{\mathrm{a}, l}$, the IN surface term will dominate the total ice formation rate, $j_{\mathrm{f}}$, in Eq. (12).

Laboratory studies lend support to the use of the shifted activity method at least for the solid dihydrate of oxalic acid (a dicarboxylic acid found in upper-tropospheric particles) immersed in aqeuous solutions (Zobrist, et al., 2006). In the LCM, a system of equations similar to Eqs (9) and (10) is solved replacing $n_{\mathrm{v}, \mathrm{a}, l}$ by the corresponding number concentration of IN particles in size bin $l$ and extending the sum in Eq. (11) to include IN.

To represent heterogeneous ice nucleation in the deposition mode, we make use of a different parametrization. Recent laboratory measurements indicate that deposition nucleation on dust particles, which are considered relatively potent tropospheric IN, may occur over a wide range of

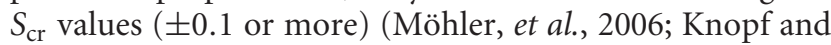
Koop, 2006), indicative of variability in IN surface properties or chemical composition of individual dust IN particles. To account for this fact, we follow Möhler, et al. (2006) and alternatively calculate the formation rate of ice crystals from

$$
\frac{\mathrm{d} n_{\mathrm{i}}}{\mathrm{d} t}=\zeta \frac{\mathrm{d} S_{\mathrm{i}}}{\mathrm{d} t} n_{\mathrm{p}}, \quad \zeta=\frac{\mathrm{d} \varphi}{\mathrm{d} S_{\mathrm{i}}}
$$

where $n_{\mathrm{p}}$ is the initial IN number concentration and $\zeta$ denotes the IN activation spectrum containing information on the $S_{\mathrm{i}}$ range over which ice nucleation occurs. $\zeta$ is defined as the fraction $\mathrm{d} \varphi$ of ice crystals nucleating from $n_{\mathrm{p}}$ in a given range of supersaturation, $\mathrm{d} S_{\mathrm{i}}$. The total time derivative $\mathrm{d} S_{\mathrm{i}} / \mathrm{d} t$ includes advective tendencies and estimated changes in the deposition rate affecting $S_{\mathrm{i}}$ during advection. Equation (13) predicts that more insoluble particles act as IN with increasing supersaturation (Meyers, et al., 1992). In practice, the small reservoir of available upper-tropospheric IN (typically $<0.01-0.1 \mathrm{~cm}^{-3}$ ) will limit the number of ice crystals resulting from heterogeneous nucleation. In contrast to immersion mode nucleation, we apply Eq. (13) with monodisperse IN $\left(r_{\mathrm{a}}=0.5 \mu \mathrm{m}\right)$, because no explicit size dependence for $\zeta$ is given by Möhler, et al. (2006); we attribute the same radius to the nucleated ice crystals at the point of their formation.

There exist a number of physical and chemical requirements necessary to enable ice formation from insoluble particles (Pruppacher and Klett, 1997). Some of these requirements are implicit in the empirical Eqs (12) and (13). Alternative IN parametrizations can be incorporated into the LCM model framework if necessary.

\subsection{Ice crystal representation}

\subsubsection{Key assumptions}

(i) The macroscopic properties of the ice phase can be deduced from the knowledge of the properties of a limited number of simulation ice particles.

The Lagrangian approach allows us to track a large total number $N_{\text {SIP }}\left(\mathcal{O}\left(10^{6}\right)\right.$ or more) of SIP individually in simulating the ice phase. Each SIP represents $10-10^{5}$ real ice crystals (typically $\mathcal{O}\left(10^{4}\right)$ ), determined by the conditions prevailing during the formation of ice crystals and the spatial model resolution. The fewer real ice crystals SIP contain on average, the more SIP are affected by a greater range of variability in meteorological conditions. In a statistical 
sense, average ice phase properties per grid box containing $N_{\mathrm{p}}$ SIP converge with increasing sample size $\propto 1 / \sqrt{N_{\mathrm{p}}}$ (section 2.3.2).

We make the simplifying assumption that each real ice crystal in a given SIP is associated with the corresponding SIP physical properties. A refinement could be to associate probability distributions of mass, habit, and other properties to the real ice crystals in each SIP. The definition of such probability distributions requires knowledge about the subgrid-scale variability in the moisture and temperature fields, among other factors known to affect mass, habit, etc. As we currently do not see the need to introduce such a more complex methodology, this is left for future research. At any rate, the fact that usually many SIPs are present in a grid box ensures a sufficiently large variability in ice crystal properties in our model.

(ii) The simulation ice particles interact with the gas phase using the volume-averaged values at the grid points.

Within a grid box volume, each SIP interacts with the volume-averaged grid point values of the Eulerian model variables $\mathbf{u}, q_{\mathrm{v}}, p, T$, among others. While the exact SIP positions are known, subgrid-scale variability of the resolved model variables is not known without further physical models. Such knowledge would be required to estimate their values at the SIP positions. We claim to use sufficiently fine spatial resolutions in our LES set-ups to keep this potential source of uncertainty small, hence we refrain from interpolating grid point values to the SIP positions. Interpolation would yield smoother fields of model variables, but would not improve the simulation results. We do not recommend applying our cloud-permitting approach using coarser spatial resolutions that compromise the resolution of a single cirrus cloud without carefully checking the effects of the unresolved variability, in particular concerning relative humidity and vertical velocity.

Modelled processes acting on each SIP are advection by the resolved wind field $\mathbf{u}$, turbulent dispersion of SIP trajectories involving a stochastic component (parametrized using EULAG's turbulence closure scheme, section 2.3.5), growth by deposition or sublimation of water vapour, sedimentation, aggregation, and radiative heating or cooling, as discussed below. The position vector, chemical composition, habit, nucleation pathway, and other variables are known for all SIP and can optionally be recorded during a simulation. A secondary ice production mechanism, the Hallett-Mossop ice multiplication process (Hallett and Mossop, 1974), is not considered in the LCM. The Hallett-Mossop process is only important in the narrow temperature range from -8 to $-3{ }^{\circ} \mathrm{C}$ and requires the presence of liquid water. Another secondary ice production process is the break-up of aggregated ice crystals (Bacon, et al., 1998). Knowledge of this pathway in the atmosphere is lacking (Cantrell and Heymsfield, 2005); it can therefore not be adequately quantified and implemented in current models.

\subsubsection{Selection of simulation ice particles}

Simulation ice particles are attributed to a certain grid point, if they reside in a volume $V_{\mathrm{b}}$ with edge lengths $\Delta x, \Delta y$, and $\Delta z$ and this grid point as centre. Figure 2 depicts how the SIPs are created in the LCM during homogeneous freezing or heterogeneous ice nucleation. The principal outline of our selection algorithm is as follows:

1. Starting point at time $t$ is a grid box with volume $V_{\mathrm{b}}$, in which SIPs may already exist.

2. During the small time step $\Delta t_{\mathrm{N}}$, ice formation rates are calculated in each size bin $l$, yielding $\mathcal{N}$ new (real) ice crystals.

3. If the concentration of newly formed crystals is smaller than $n_{\min }$, the formation event is ignored, to keep the total number of SIP tractable. On the other hand, an individual SIP should not represent more than $n_{\max }$ real ice crystals to ensure a sufficiently high resolution of ice phase processes. Therefore, if in size bin $l$ :

(a) $\mathcal{N} / V_{\mathrm{b}}<n_{\text {min }}$, then ice crystals that would form are neglected, but may form again in the subsequent time step.

(b) $n_{\text {min }} \leq \mathcal{N} / V_{\mathrm{b}} \leq n_{\max }$, then all new ice crystals are represented by one SIP containing $\mathcal{N}_{i}=\mathcal{N}$ real ice crystals.

(c) $\mathcal{N} / V_{\mathrm{b}}>n_{\max }$, then ice crystals that form are too numerous to be represented by only one SIP; $m_{n}$ SIPs are created until $\mathcal{N}_{i, m_{n}} / V_{\mathrm{b}} \leq n_{\max }$.

Typical values for $n_{\min }$ and $n_{\max }$ are $10-100 \mathrm{~m}^{-3}$ and $5 \times 10^{4}-10^{5} \mathrm{~m}^{-3}$, respectively.

Unresolved variability in the variables controlling ice formation will modulate the nucleation probability in the grid box locally, so we distribute the added SIP randomly within $V_{\mathrm{b}}$. The SIP position vectors may be viewed as average positions of all corresponding real ice crystals.

As atmospheric conditions and ice phase properties change continuously during a simulation run, the actual total number of SIPs that have to be simulated to obtain robust statistical results for the ice phase properties must be determined empirically prior to each new simulation case. The ideal value of $N_{\text {SIP }}$ is a trade-off between statistical accuracy and computational effort.

Figure 3 presents 2D simulation results of a midlatitude cirrus cloud subject to weak synoptic uplift. For the different runs, $n_{\min }$ is varied between 0.1 and $50 \mathrm{~m}^{-3}$, resulting in $1.1 \times 10^{6}-8.5 \times 10^{6}$ total SIPs. In the upper panel, the ice water content (cloud ice mass per unit volume of air in each grid box, IWC) is shown for the runs with the fewest and most SIPs. Visual inspection reveals differences in the distributions of the fall streaks (yellow and red) and a more patchy appearence in the low resolution case. In the lower panel, horizontal averages of the IWC field and the relative deviation of individual runs from the reference run with $4.5 \times 10^{6}$ SIPs are shown.

Generally, we find that with increasing number of SIPs exceeding the value used in the reference case, the results converge (see $\triangle \mathrm{IWC}$ profiles, Figure 3 ). Significant departures from the reference case are found for the low-resolution runs, leading to relative $\triangle I W C$ values of $\sim 200-300 \%$ in the nucleation zone in the upper part of the cloud $(\sim 9 \mathrm{~km})$ and in the sublimation zone at the cloud base $(\sim 6.5 \mathrm{~km})$. We identify two different mechanisms that may cause these relatively large deviations. At the cloud top, the choice of a higher value of $n_{\min }$ (leading to fewer SIPs) retards the onset of ice formation. Therefore, the supersaturation reaches higher peak values, increasing the amount of water vapour available for deposition and leading to higher IWC values. At the cloud base, for low resolution, 


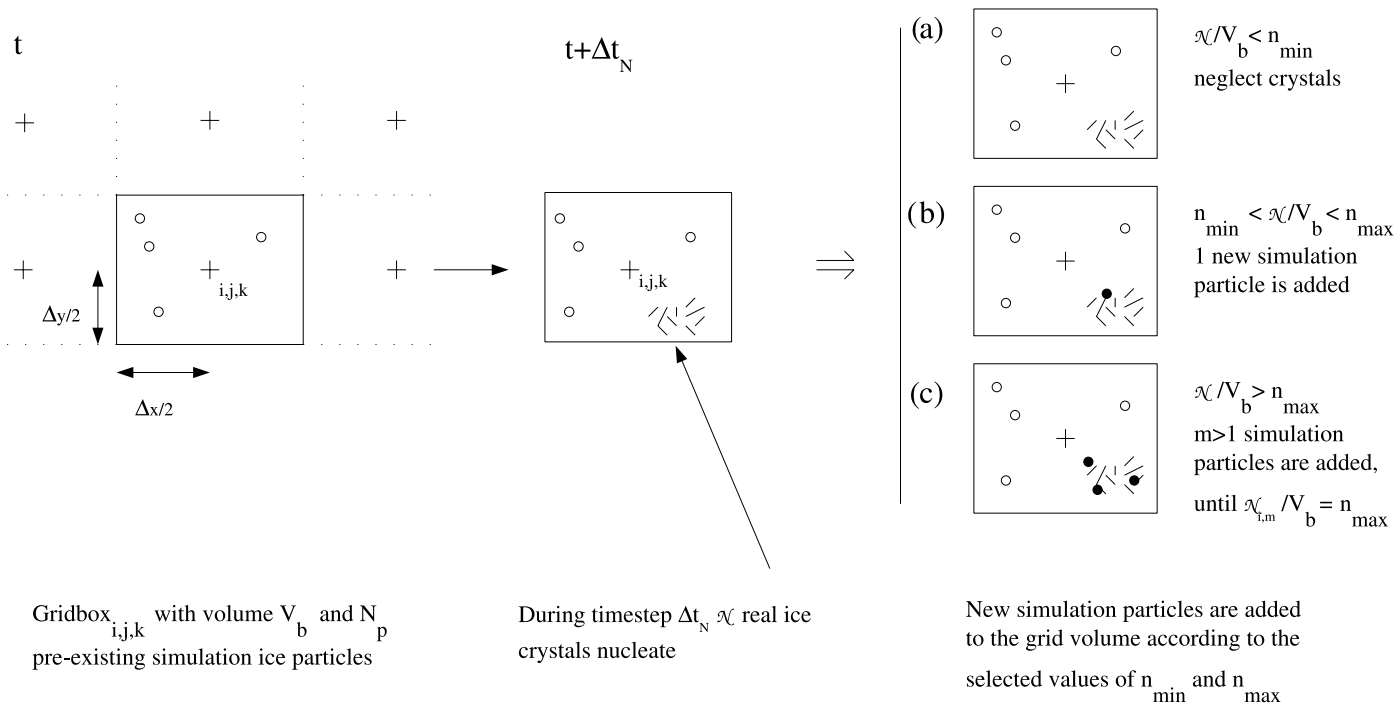

Figure 2. Schematic illustrating the generation of simulation ice particles due to ice crystal formation during one time step, $\Delta t_{\mathrm{N}}$, in a staggered grid box. Unfilled (filled) circles mark pre-existing (newly formed) SIPs. For details, see text.
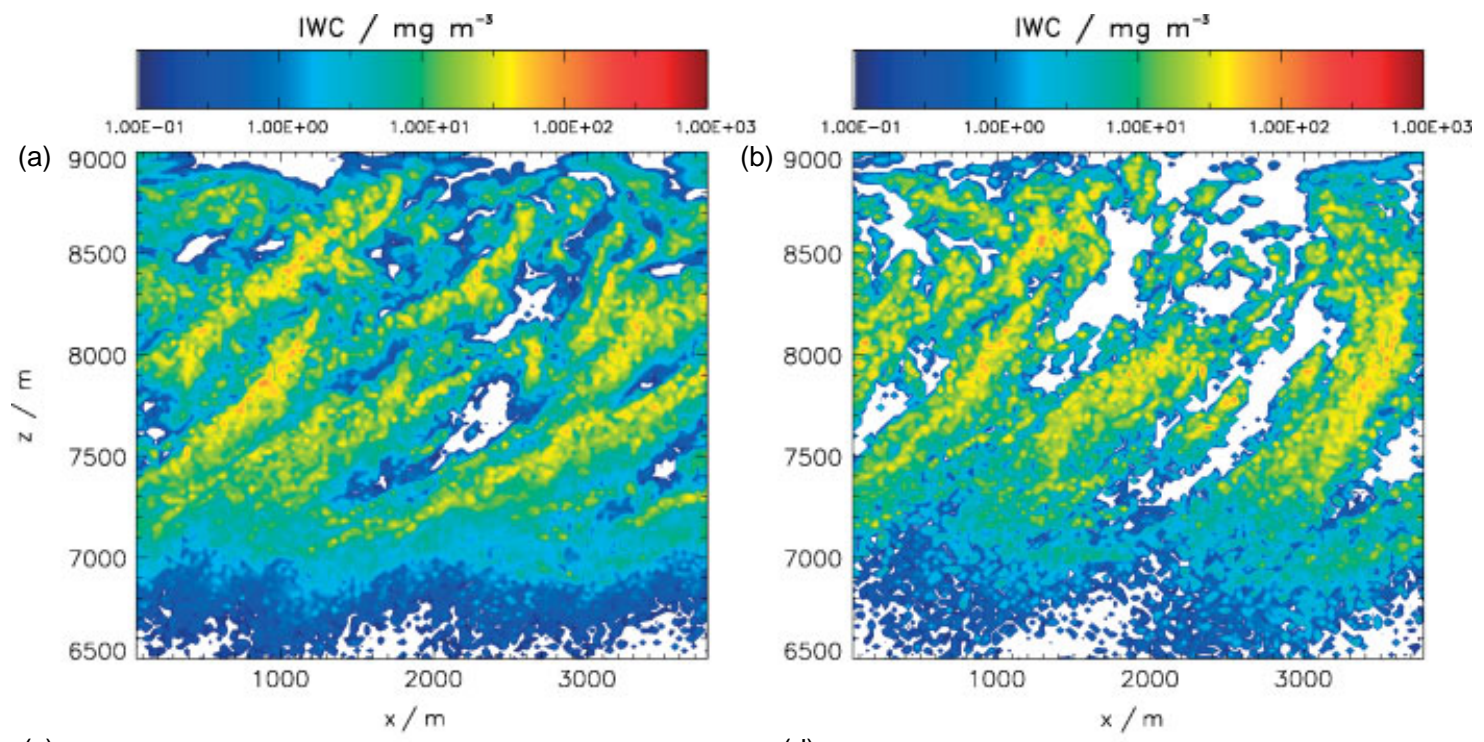

(c)
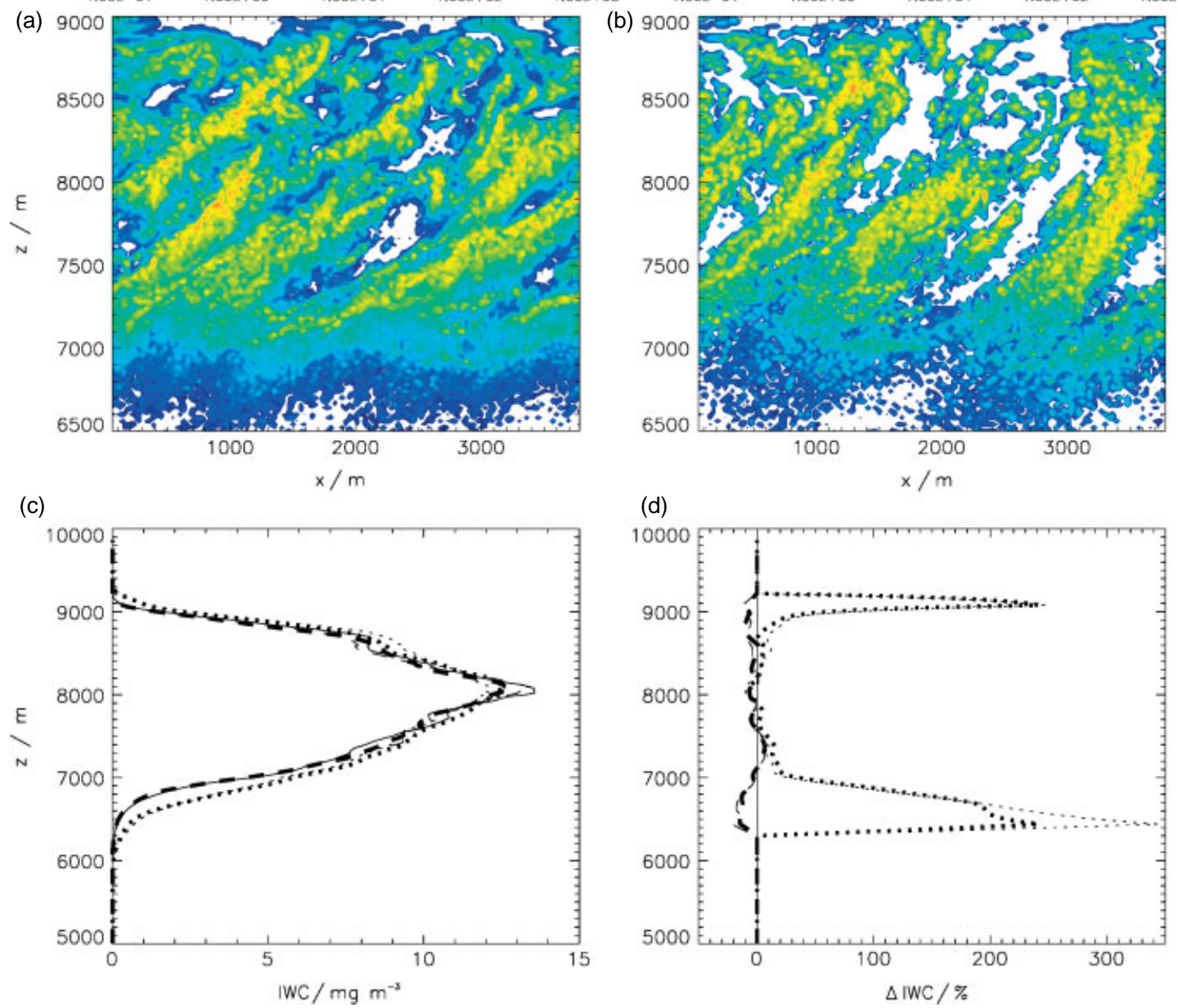

Figure 3. Section of ice water content in a developed cirrus using (a) $8.5 \times 10^{6}$ and (b) $1.1 \times 10^{6}$ SIPs. (c) shows horizontally averaged vertical IWC profiles for the simulations using $1.1 \times 10^{6}$ (thin dots), $3.3 \times 10^{6}$ (bold dots), $4.5 \times 10^{6}$ (solid, reference run), $5.6 \times 10^{6}$ (bold dashes), and $8.5 \times 10^{6}$ (thin dashes) SIPs, and (d) shows \%age deviations from the reference run. 
SIPs will contain relatively large numbers of real ice crystals. As the number of SIPs is small, they populate only a few grid boxes and sublimation of the first SIPs entering a grid box will quickly bring the water vapour there to saturation due to the large ice crystal number density. This inhibits sublimation of SIPs subsequently entering these grid boxes, keeping the IWC high. By contrast, for high resolution, more SIPs are created which are more likely distributed among many grid boxes. Because in this case each SIP contains relatively few real ice crystals, the air in the grid boxes may be expected to stay subsaturated for a longer time, allowing subsequent SIPs to sublimate, decreasing the IWC.

\subsubsection{Depositional growth and sublimation}

Growth and sublimation processes of single ice crystals of mass $m_{i}$ are governed by the deposition equation

$$
\begin{aligned}
\frac{\mathrm{d} m_{i}}{\mathrm{~d} t}= & 4 \pi C_{i} D_{\mathrm{v}, \mathrm{eff}}^{\prime}\left(p_{\mathrm{v}}-p_{\mathrm{i}, \mathrm{s}}^{\prime}\right) \\
& -\frac{H_{\mathrm{R}, i} D_{\mathrm{v}, \mathrm{eff}}^{\prime} p_{\mathrm{i}, \mathrm{s}}^{\prime}}{\kappa_{\mathrm{d}}^{\prime} T}\left(\frac{L_{\mathrm{s}}}{R_{\mathrm{v}} T}-1\right), \\
D_{\mathrm{v}, \text { eff }}^{\prime}= & \frac{D_{\mathrm{v}}^{\prime}}{\frac{D_{\mathrm{v}}^{\prime} L_{\mathrm{s}} p_{i, \mathrm{~s}}^{\prime}}{\kappa_{d}^{\prime} T}\left(\frac{L_{\mathrm{s}}}{R_{\mathrm{v}} T}-1\right)+R_{\mathrm{v}} T},
\end{aligned}
$$

including latent heat effects and net radiative heating of ice crystals. The latter involves the net heating rate $H_{\mathrm{R}, i}$ (section 2.4), represented by the second term on the righthand side of Eq. (14). Furthermore, $C_{i}$ is the ice crystal capacitance replacing $r_{i}$ for non-spherical ice particles (Appendix 6), $L_{\mathrm{s}}$ is the latent heat of sublimation, and $p_{\mathrm{i}, \mathrm{s}}^{\prime}$ is the saturation vapour pressure over the ice crystal surface (Murphy and Koop, 2005) including a Kelvin correction (Kärcher, 2003). Finally, $D_{\mathrm{v}}^{\prime}$ and $\kappa_{\mathrm{d}}^{\prime}$ denote the corrected $\mathrm{H}_{2} \mathrm{O}$ diffusion coefficient in air and corrected thermal conductivity of air, respectively:

$$
\begin{aligned}
D_{\mathrm{v}}^{\prime} & =f_{\mathrm{v}, i} \beta_{\mathrm{v}, i} D_{\mathrm{v}}, \\
\kappa_{\mathrm{d}}^{\prime} & =f_{\mathrm{th}, i} \beta_{\mathrm{th}, i} \kappa_{\mathrm{d}} ;
\end{aligned}
$$

these corrections comprise ventilation effects, $f$ (Appendix 6), and the transition from the free molecular to diffusion-limited growth regime, $\beta$ (Appendix 6). Temperature-dependent latent heat, $L_{\mathrm{s}}$, and thermal conductivity of air, $\kappa_{\mathrm{d}}$, are taken from the literature (Jacobson, 1999).

We do not account for subgrid-scale fluctuations of the supersaturation $\left(p_{\mathrm{v}}-p_{\mathrm{i}, \mathrm{s}}^{\prime}\right)$ in Eq. (14) (see section 2.3.1). Stochastic condensation theories have been applied to warm clouds, for instance, to explain the broadening of droplet size distributions (Shaw, 2003). We hope to study basic properties of the turbulent supersaturation and the impact on ice PSDs in cirrus in future work in order to decide upon the need and optimal way to link stochastic elements to ice crystal growth in a large eddy model framework.

Equation (14) is coupled to the gas phase via

$$
\frac{\mathrm{d} n_{\mathrm{v}}}{\mathrm{d} t}=-\frac{1}{m_{\mathrm{v}} V_{\mathrm{b}}} \sum_{i=1}^{N_{\mathrm{p}}} \frac{\mathrm{d} m_{i}}{\mathrm{~d} t} \mathcal{N}_{i},
$$

where $N_{\mathrm{p}}$ is the number of SIPs in the grid box and $m_{\mathrm{v}}$ is the mass of a water molecule. The system of Eqs (14) and (18) is solved using the analytic predictor of condensation scheme (Jacobson, 1999).

Latent heat release during ice crystal growth changes the potential temperature in Eq. (3) via the latent heating rate $H_{\mathrm{H}}$,

$$
H_{\mathrm{H}}=-\frac{L_{\mathrm{s}}}{c_{p}}\left(\frac{p_{00}}{p}\right)^{\kappa} \frac{\mathrm{d} q_{\mathrm{v}}}{\mathrm{d} t},
$$

with the reference pressure $p_{00}=1000 \mathrm{hPa}$ and $\mathrm{d} q_{\mathrm{v}} / \mathrm{d} t$ taken from Eq. (18). The latent heat of particle phase change (liquid to ice and vice versa) is neglected because of its very small contribution to the thermal budget in cirrus conditions.

As an option, we allow for trapping of $\mathrm{HNO}_{3}$ in growing ice particles using the theory developed by Kärcher, et al. (2009a). The trapping mechanism is required to accurately simulate the partitioning of $\mathrm{HNO}_{3}$ between the gas and ice phase in the presence of cirrus clouds. Trapping is described by an equation similar to Eq. (14) for the mass of $\mathrm{HNO}_{3}$ molecules in the ice crystal, in which the saturation vapour pressure term is ignored but the diffusion correction term $\beta$ is replaced by a suitable trapping efficiency. Release of trapped $\mathrm{HNO}_{3}$ from sublimating ice crystals is also accounted for. Latent heat effects caused by $\mathrm{HNO}_{3}$-ice interactions are negligible owing to the small $\mathrm{HNO}_{3} / \mathrm{H}_{2} \mathrm{O}$ molar ratios in ice crystals $\left(\mathcal{O}\left(10^{-5}\right)\right.$ or less $)$.

\subsubsection{Ice crystal habits}

Growth rates, sedimentation velocities, and radiative heating rates of ice crystals depend on their habit. Recent laboratory studies (Bailey and Hallett, 2004, 2009) have addressed this issue. However, habits of atmospheric ice crystals and their changes forced by variations of pressure, temperature, relative humidity, and perhaps other parameters cannot yet be predicted from first principles (Kärcher and Spichtinger, 2009).

We base our treatment of ice crystal habits on empirical relations between each ice crystal's mass $m_{i}$, projected area $A_{i}$, and maximum dimension $D_{i}$, which are deduced from a few field studies (Mitchell, 1996; Heymsfield, et al., 2002):

$$
\begin{aligned}
& m_{i}=\alpha D_{i}^{\beta}, \\
& A_{i}=\gamma D_{i}^{\sigma} ;
\end{aligned}
$$

the coefficients $\alpha, \beta, \gamma$, and $\sigma$ depend on the type of habit. Cloud imaging probes employed in airborne measurements of cirrus have been used to study the size dependence of habits. Guided by such observations, different habits are assumed in the LCM for ice crystals in individual SIP depending on their maximum dimension (Table AII), enabling the online simulation of a distribution of habits and their effect on growth, aggregation, and radiative transfer.

The use of Eqs (20) and (21) for each ice crystal habit is a simplification. In nature, there is almost certainly a distribution of these relationships, as the individual crystals grow in different ways with different histories. Considering such a distribution might lead to enhanced aggregation.

\subsubsection{Trajectories of simulation ice particles}

Ice crystals are advected by the grid-scale wind field $\mathbf{u}$ and move relative to the surrounding air due to gravitational 
sedimentation with the terminal fall velocity $\mathbf{v}_{\mathrm{t}}$ (Appendix 6). Therefore, the trajectory vector $\mathbf{x}_{\mathrm{p}, i}$ of a SIP may be calculated as

$$
\frac{\mathrm{d} \mathbf{x}_{\mathrm{p}, i}}{\mathrm{~d} t}=\mathbf{u}+\left(\widetilde{\mathbf{u}}_{i}+\mathbf{v}_{\mathrm{t}, i}\right) .
$$

In Eq. (22), $\widetilde{\mathbf{u}}_{i}$ is an additional turbulent velocity component, derived from the turbulent kinetic energy per unit mass, TKE (Schilling, et al., 1996). The latter is taken from EULAG's subgrid-scale closure scheme and represents unresolved wind velocity fluctuations, expressed as

$$
\widetilde{\mathbf{u}}_{i}(t)=R_{\mathrm{L}} \widetilde{\mathbf{u}}_{i}\left(t-\Delta t_{\mathrm{M}}\right)+\mathbf{u}_{i}^{*}(t),
$$

with

$$
\mathbf{u}_{i}^{*}(t)=\sqrt{1-R_{\mathrm{L}}^{2}} \sigma_{u} \xi
$$

$R_{\mathrm{L}}$ is the Lagrangian autocorrelation coefficient

$$
R_{\mathrm{L}}=\exp \left(-\Delta t_{\mathrm{M}} / \tau_{\mathrm{L}}\right)
$$

where $\tau_{\mathrm{L}}=K_{m} / \mathrm{TKE}$ is the Lagrangian fluid time-scale, and $K_{m}$ is the diffusion coefficient for momentum. In Eq. (23), $\mathbf{u}_{i}^{*}$ is a stochastic velocity component obtained from a Monte Carlo process and $\xi$ is a normally distributed random number with zero mean and unity standard deviation. The velocity standard deviations are obtained from

$$
\left|\sigma_{u}\right|=\sqrt{\mathrm{TKE}}
$$

This approach allows us to estimate the subgrid-scale dispersion of individual SIP trajectories consistent with the EULAG model physics.

\subsubsection{Aerosol core return and removal of simulation ice particles}

Ice crystals sublimate in subsaturated conditions and eventually release their aerosol cores upon which they have nucleated. These cores could either be fully liquid in the case of homogeneous freezing, or insoluble in the case of heterogeneous ice nucleation. In the former case, the liquid aerosol core contains a certain number of water molecules in order to stay in equilibrium with the ambient relative humidity.

Nucleation pathways of the ice crystals in each SIP are stored in the LCM by default. The ice-forming particle core is transferred back into the appropriate size bin of the respective aerosol population, once non-aggregated ice crystals completely sublimate. In the case of aggregated ice crystals (section 4), only the aerosol core of the first collecting ice crystal is memorised, ignoring those of further collected ice crystals for computational reasons.

Ice crystals originating from liquid aerosol particles of a given size class are regarded as completely sublimated, if the number of $\mathrm{H}_{2} \mathrm{O}$ molecules in the core particle falls below the number dictated by the ambient relative humidity in the grid box where sublimation occurs. Ice crystals originating from solid IN cores are regarded as fully sublimated, if the number of $\mathrm{H}_{2} \mathrm{O}$ molecules on them falls below the threshold of 1000 . The results are not sensitive to this assumed lower limit threshold.

The SIPs are removed from the calculation after core return. Optionally, we can continue to carry the SIPs and their association with the IN cores in the LCM to enable the treatment of secondary ice formation by preactivated IN.

\subsubsection{Ensemble averages for ice phase properties}

Grid-box average values of the ice phase properties are calculated by taking ensemble averages over all $N_{\mathrm{p}}$ SIPs in a grid box of volume $V_{\mathrm{b}}$, e.g.

$$
n_{\mathrm{i}}=\frac{1}{V_{\mathrm{b}}} \sum_{i=1}^{N_{\mathrm{p}}} \mathcal{N}_{i}, \quad \text { IWC }=\frac{1}{V_{\mathrm{b}}} \sum_{i=1}^{N_{\mathrm{p}}} m_{i} \mathcal{N}_{i}
$$

for the ice crystal number concentration $n_{\mathrm{i}}$ and the ice water content. The number-weighted mean maximum dimension of ice crystals, $\bar{D}$, is given by

$$
\bar{D}=\sum_{i=1}^{N_{\mathrm{p}}} D_{i} \mathcal{N}_{i} / \sum_{i=1}^{N_{\mathrm{p}}} \mathcal{N}_{i} .
$$

Ensemble averages of other variables follow similarly.

\subsection{Radiation}

As a first step, a 1D radiative transfer scheme is applied in the EULAG-LCM, based on the parametrizations proposed by $\mathrm{Fu}$ (1996). This scheme is well documented and is known to give robust results, but cannot make full use of the detailed microphysical information provided by the LCM. We intend to implement a more detailed radiative transfer parametrization in future work.

Concerning radiative effects on ice crystal growth, we calculate the radiative properties of the individual SIPs according to assumptions made in the LCM regarding the size and shape of the real ice crystals.

\subsubsection{Radiative transfer parametrization}

The radiative heating term $H_{\mathrm{R}}$ for use in Eq. (3) is obtained in each grid box from a radiative transfer scheme based on the $\delta$-four-stream approximation for plane parallel atmospheres in the independent column approximation (Liou, et al., 1988). The electromagnetic spectrum is divided into six bands in the solar and 12 bands in the infrared wavelength region. Non-grey gaseous absorption is considered using the correlated $k$-distribution method ( $\mathrm{Fu}$ and Liou, 1992). In the short-wave spectrum, absorption by $\mathrm{H}_{2} \mathrm{O}, \mathrm{O}_{3}, \mathrm{CO}_{2}$ and $\mathrm{O}_{2}$ is included, and in the infrared, absorption by $\mathrm{H}_{2} \mathrm{O}, \mathrm{O}_{3}$, $\mathrm{CO}_{2}, \mathrm{CH}_{4}$ and $\mathrm{N}_{2} \mathrm{O}$. Vertical trace gas concentration profiles are prescribed as fixed background values, except for $\mathrm{H}_{2} \mathrm{O}$ $\left(q_{\mathrm{v}}\right)$, which is explicitly calculated in the EULAG-LCM.

Assuming hexagonal ice crystals with column length $D_{i}$, width $W_{i}$ and aspect ratio $\mathcal{A}_{i}=W_{i} / D_{i}$, the single-scattering properties are parametrized consistent with the assumptions made by $\mathrm{Fu}$ (1996) in the transfer code concerning the generalized effective size $D_{\text {ge }}$ in each model grid box,

$$
\begin{aligned}
D_{\mathrm{ge}} & =\frac{\int_{D_{\min }}^{D_{\max }} W^{2} D n(D) \mathrm{d} D}{\int_{D_{\min }}^{D_{\max }}\left(W D+\frac{\sqrt{3}}{4} W^{2}\right) n(D) \mathrm{d} D} \\
& =\frac{\sum_{i=1}^{N_{\mathrm{p}}}\left(\mathcal{A}_{i} D_{i}\right)^{2} D_{i} \mathcal{N}_{i}}{\sum_{i=1}^{N_{\mathrm{p}}}\left\{\left(\mathcal{A}_{i} D_{i}\right) D_{i}+\frac{\sqrt{3}}{4}\left(\mathcal{A}_{i} D_{i}\right)^{2}\right\} \mathcal{N}_{i}},
\end{aligned}
$$


where $n(D)$ denotes the ice particle size distribution. Equation (29) is used together with the IWC as input for the radiation module from the LCM. $T$ and $p$ are also input from the dynamical core. Standard atmospheric profiles above and below the integration area are taken from Anderson, et al. (1986). In transition zones above and below the model domain (thicknesses of about $1 \mathrm{~km}$ ), the EULAG and ambient profiles are matched by linear interpolation.

\subsubsection{Radiative effects on ice crystal growth}

Growth or sublimation of ice crystals may be modified by radiative heating or cooling of the crystal's surface (Hall and Pruppacher, 1976; Stephens, 1983; Ramaswamy and Detwiler, 1986; Gierens, 1992; Gu and Liou, 2000), predominantely at small (less than a few percent) ice sub- or supersaturation. Especially in lower regions of cirrus clouds, where large ice crystals prevail, absorption of radiation may heat the crystal surfaces and increase the ice saturation vapour pressure $p_{\mathrm{i}, s}^{\prime}$, thereby enhancing sublimation rates or slowing mass growth rates. Radiative cooling may occur at cloud tops and may enhance ice particle growth. These processes are represented by the second term on the righthand side of Eq. (14), using the net heating rates $H_{\mathrm{R}, i}$.

To calculate $H_{\mathrm{R}, i}$, we follow Stephens (1983):

$$
\begin{aligned}
H_{\mathrm{R}, i}= & A_{\mathrm{c}}\left(D_{i}, \Pi_{i}\right) \\
& \times \int_{0}^{\infty} \sigma_{\mathrm{abs}, \lambda}\left(D_{i}, \Pi_{i}\right)\left\{F_{\lambda}^{+}+F_{\lambda}^{-}-2 \pi B_{\lambda}\left(T_{\mathrm{S}}\right)\right\} \mathrm{d} \lambda .
\end{aligned}
$$

Here, $A_{c}$ is the ice crystal cross-sectional area, which is a function of maximum dimension $D_{i}$ and habit $\Pi_{i}, \sigma_{\mathrm{abs}, \lambda}$ is the spectral absorption cross-section for a given $D_{i}$ and $\Pi_{i}$, and $B_{\lambda}\left(T_{\mathrm{S}}\right)$ is the Planck emissivity function evaluated at the temperature $T_{\mathrm{S}}$ of the ice crystal surface. Hall and Pruppacher (1976) provide an analytical estimate for $T_{S}$; we set $T_{\mathrm{S}}=T$ in evaluating $H_{\mathrm{R}, i}$. This temperature correction is small and results in changes of $B_{\lambda}$ that are much smaller than the uncertainties in estimating the net short-wave and long-wave radiative flux terms $F_{\lambda}^{ \pm}$using the $\delta$-four-stream approximation.

To calculate the net upward and downward directed fluxes, $F_{\lambda}^{+}$and $F_{\lambda}^{-}$, respectively, we use the output of the radiation routine, which provides these quantities in $M$ distinct wavelength bands. We therefore replace the integral in Eq. (30) by a summation over the appropriate bands:

$$
\begin{aligned}
H_{\mathrm{R}, i} \cong & A_{\mathrm{c}}\left(D_{i}, \Pi_{i}\right) \\
& \times \sum_{m=1}^{M} \sigma_{\mathrm{abs}, m}\left(D_{i}, \Pi_{i}\right)\left\{F_{m}^{+}+F_{m}^{-}-2 \pi B_{m}\left(T_{\mathrm{S}}\right)\right\} .
\end{aligned}
$$

Values for $\sigma_{\mathrm{abs}, \lambda}$ and $A_{\mathrm{c}}$ are taken from the database provided by Yang, et al. (2005), and $\sigma_{\mathrm{abs}, m}$ is a derived average absorption efficiency weighted with the Planck function in the $m$ th wavelength band. $B_{m}\left(T_{\mathrm{S}}\right)$ is the spectrally averaged Planck function.

\section{Validation of basic microphysical processes}

We first validate the LCM without considering transport, sedimentation, and aggregation of the ice phase. The important microphysical processes are aerosol dissolutional growth, evaporation, and freezing, and ice formation and depositional growth and sublimation. These processes, in particular the nucleated number of ice crystals, are very sensitive to differences in their numerical representation.

We run the LCM in a parcel mode and compare the results with the APSCm (Kärcher, 2003), from which the aerosol and ice formation components in the LCM have been partly derived (section 2.2). The main difference between the LCM and the APSCm is the fundamentally different treatment of the ice phase itself. While the LCM tracks $N_{\text {SIP }}=20000$ SIPs for the purpose of this validation exercise, as described in section 2.3, the APSCm uses a bin scheme along with the moving centre grid not only for liquid aerosols, but also for ice crystals. Otherwise, microphysical parameters (aerosol properties, homogeneous freezing rates, assumed ice crystal habit, and $\mathrm{H}_{2} \mathrm{O}$ deposition coefficient on ice) are chosen to be identical. Therefore, any difference between these two models is related to the different treatment of how nucleated aerosol particles are transferred into ice crystals and how the latter are allowed to interact with the gas phase water vapour.

For convenience, we select a comparison of parcel simulations already documented in the cirrus parcel model intercomparison project carried out in the framework of the Global Energy and Water Cycle (GEWEX) Global Cloud System Studies (GCSS) (Lin, et al., 2002, their case Ch020) . Ice initiation by homogeneous freezing of solution droplets was simulated in an air parcel ascending adiabatically from $p=170 \mathrm{hPa}$ and $T=213 \mathrm{~K}$ with a constant updraught velocity of $20 \mathrm{~cm} \mathrm{~s}^{-1}$. Figure 4 shows the results of the model runs. Deviations between the LCM (solid curve) and the APSCm results (dashed curve) for IWC and RHI as a function of lifted distance are very small, demonstrating that the treatment of ice phase nucleation and growth processes have been correctly implemented in the LCM.

Both results fit qualitatively well into the predicted ranges of the other participating models (grey areas). Quantitatively, however, a large spread was found. Lin, et al. (2002) have pointed out that homogeneous freezing rates, aerosol solubility, and in particular the small ice crystal growth rates controlled by the deposition coefficient (which varied widely among different models) were largely responsible for the differences in the predicted ice phase properties.

\section{Particle-based aggregation algorithm}

Aggregation occurs if ice crystals in a cloud collide and eventually stick together, forming crystals of larger sizes and more complex habits. Several laboratory studies investigated the formation of ice crystal aggregates (Hosler and Hallgren, 1960; Hobbs, 1965; Keith and Saunders, 1989). An important parameter is the aggregation efficiency, $E_{\mathrm{agg}}$, describing the probability that a close encounter of two ice crystals results in an aggregation event. The efficency is composed of a hydrodynamical part and a molecular sticking probability. The former is controlled by the flow field around sedimenting ice crystals. The latter is affected by the molecular processes that lead to the formation of bonds between the molecules of the surfaces in contact. The actual value of $E_{\mathrm{agg}}$ employed in cirrus models also depends on the type of aggregation model realised to simulate this process, e.g. whether a single particle approach is used (as 

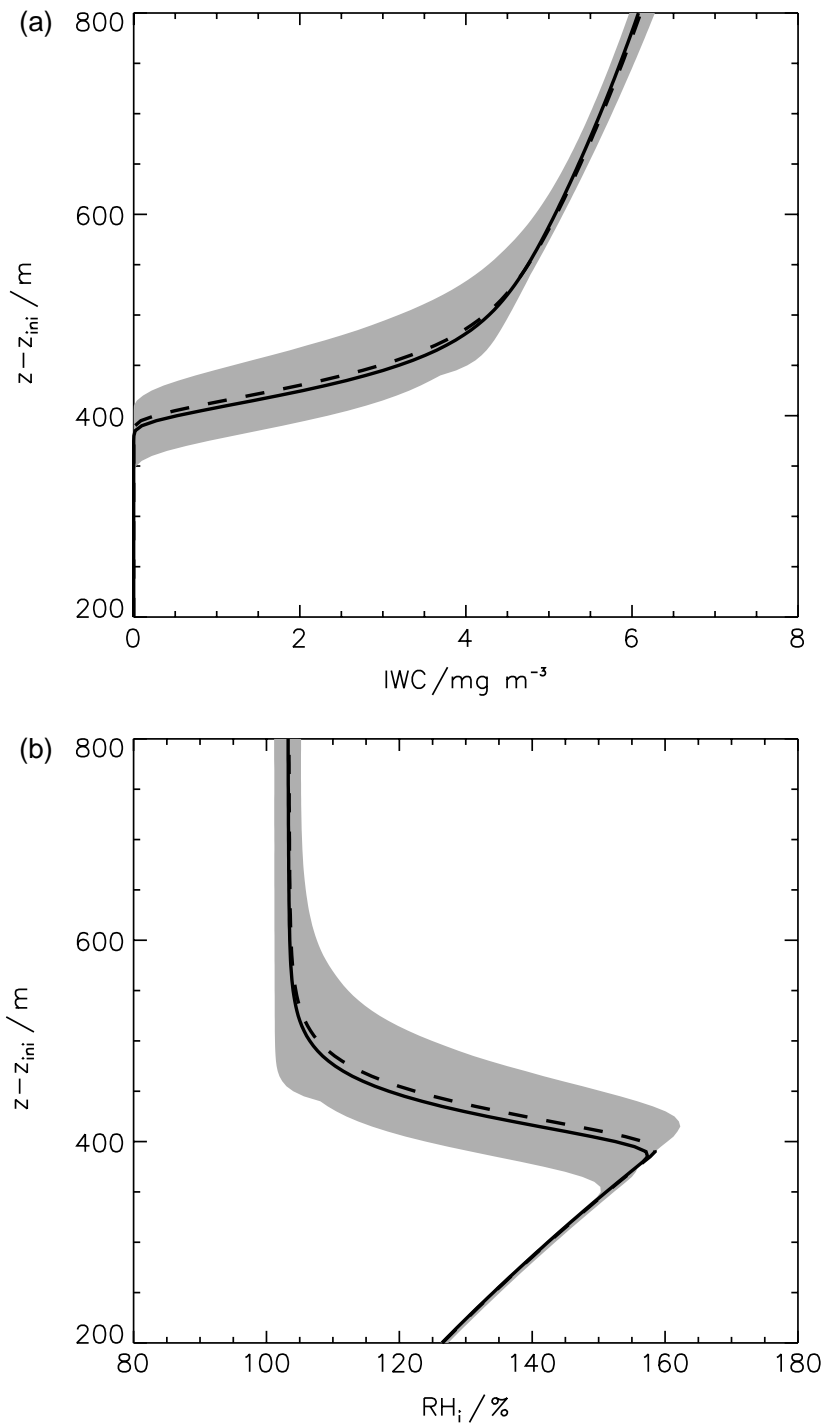

Figure 4. Results from the cirrus parcel model intercomparison study (Lin, et al., 2002) for (a) IWC and (b) RHI as function of the vertical parcel displacement relative to the initialisation height $z_{\text {ini }}$ : the ranges of the published results from various models (grey shading), and the APSCm (dashed) and LCM (solid) results.

in the LCM, which explicitly describes the kinetics of ice particle collisions by differential sedimentation of SIPs) or whether the stochastic collection equation is solved (which uses a mean field approach relying on the grid box averaged ice number concentrations; here, additional assumptions about the collision kinetics must be made, which affect the $E_{\text {agg }}$ values to be used).

The underlying mechanisms controlling the hydrodynamical and microphysical parts of $E_{\mathrm{agg}}$ is still under debate. Concerning the latter, transient melting of ice surface layers due to local pressure increases during the collision, the presence of a quasi-liquid layer on the ice crystal surfaces at higher temperatures, and a sintering process minimising the surface energy of the colliding crystals, have been discussed in the literature (Meakin, 1992; Field, et al., 2006). Aggregation may also be facilitated by mechanical interlocking of branched (large) ice crystal types, or electrostatic effects, keeping the crystals in constant relative position after a collision (Field, 1999). Concerning the hydrodynamical part, the interaction of the flows around pairs of sedimenting particles is not yet understood. This interaction likely introduces a size-dependence of $E_{\mathrm{agg}}$, which has been estimated for liquid droplets (Pruppacher and Klett, 1997) but is unknown for ice crystals.

Results of different experimental studies on the efficiency of aggregation remain inconclusive. Hosler and Hallgren (1960) observe a strong temperature dependence of $E_{\text {agg }}$ with a maximum at $-11^{\circ} \mathrm{C}$, decreasing considerably with decreasing T. Mitchell (1988) attributes this dependence to a shift in the abundance of different ice crystal shapes at different temperatures. Rauber (1987) has shown that some aggregation was almost always observed whenever planar dentritic crystals and/or spatial dendrites were present in snowfall. Cloud particle images obtained during airborne measurements clearly show aggregated bullet rosettes below $-40^{\circ} \mathrm{C}$ (Field and Heymsfield, 2003). Experimental values for the hydrodynamical collision efficiency with which snowflakes and ice spheres collect small ice crystals at warm temperatures $(>253 \mathrm{~K})$ indicate $E_{\text {agg }}$ values in the range $0.05-0.5$, assuming a microphysical sticking efficiency of unity. Ground-based measurements of $E_{\mathrm{agg}}$ may not be applicable to cirrus, because the habits of snowflakes and ice crystals are significantly different. To the best of our knowledge, data for both components of $E_{\text {agg }}$ valid in cirrus conditions are not available in the literature.

In bin microphysical schemes, aggregation is often described via the stochastic collection equation (Khain and Sednev, 1995; Pruppacher and Klett, 1997):

$$
\frac{\mathrm{d} n_{k}}{\mathrm{~d} t}=\frac{1}{2} \sum_{i+j=k} K_{i j} n_{i} n_{j}-n_{k} \sum_{i} K_{k i} n_{i} .
$$

The temporal evolution of the number concentration, $n_{k}$, of ice crystals of size $k$ is governed by a production rate (first term on the right-hand side) if type $i$ and $j$ ice crystals aggregate to form ice crystals of size $k$, and a loss rate (second term) if type $k$ ice crystals are collected by ice crystals of size $i$. The collection kernel, $K_{i j}$, contains the physics of the problem and determines the rate of aggregation between $(i, j)$ pairs of ice crystals.

Aggregation in cirrus clouds is mainly caused by differential sedimentation. Turbulent mixing in unresolved convective cells could enhance the collision efficiency over the value caused by differential sedimentation and hence the total rate of aggregation. Below, we argue that aggregation induced by turbulence may be less important, considering the rather low turbulence levels in most natural cirrus clouds compared to lower-level (warm) clouds. This may not hold for convectively generated (anvil) cirrus or newly formed contrails.

A physical model decribing the enhancement of the collision efficiency by turbulent acceleration of inertial, nonspherical cirrus ice crystals is not available in the literature, although studies exist for warm clouds and for spherical droplets with radii below $30 \mu \mathrm{m}$ (Khain, et al., 2007; Pinsky, et al., 2008). One study (Franklin, et al., 2007) shows that an increase of the turbulence intensity leads to a broadening of cloud particle size distributions. In that study, substantial enhancements of the aggregation rate due to turbulence have been found for eddy dissipation rates exceeding $\sim 100 \mathrm{~cm}^{2} \mathrm{~s}^{-3}$. Values in cirrus are typically $\mathcal{O}(1) \mathrm{cm}^{2} \mathrm{~s}^{-3}$, or smaller, according to aircraft data (Quante and Starr, 2002), so we may conjecture that turbulence has only a small effect on aggregation in stratiform cirrus, supporting Westbrook, et al. (2004) and justifying the approach taken in the LCM. 


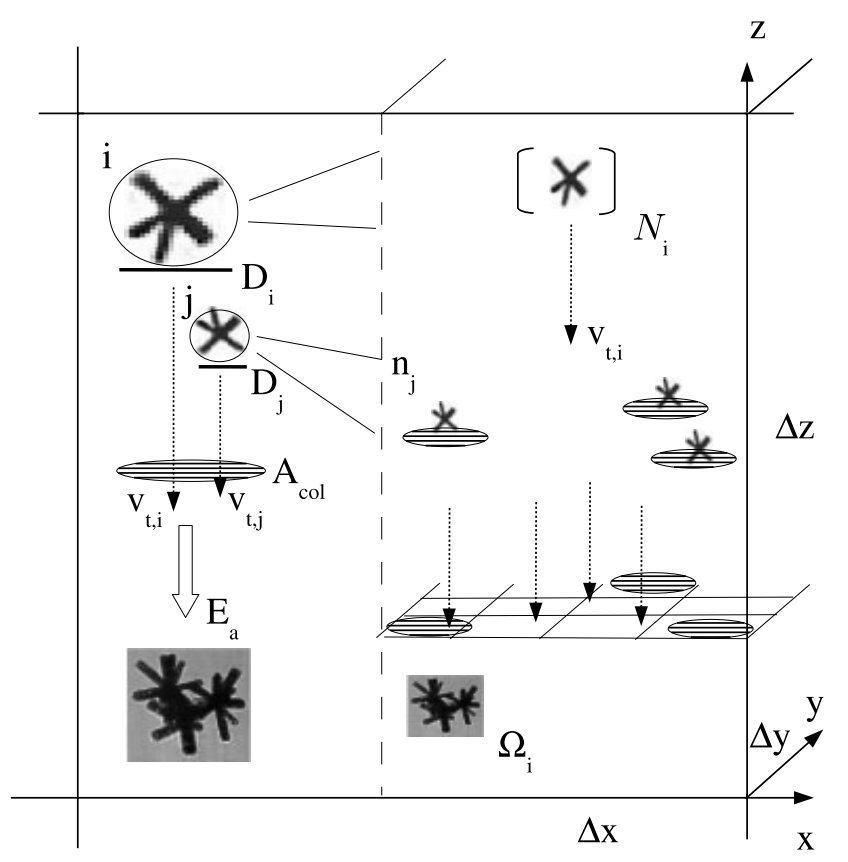

Figure 5. Schematic illustrating the representation of aggregation by differential sedimentation as realised in the LPT within a grid box with edge lengths $\Delta x, \Delta y$ and $\Delta z$. Grey ellipses indicate effective collision areas between particle pairs. For details, see text.

Aggregation by differential sedimentation occurs if large ice crystals sediment and collide with smaller, slower sedimenting ice crystals along their trajectory (left of Figure 5). This capture process is commonly described using the geometric sweep-out kernel:

$$
K_{i j}=\pi\left(r_{i}+r_{j}\right)^{2}\left|v_{\mathrm{t}, i}-v_{\mathrm{t}, j}\right| E_{\mathrm{agg}},
$$

defining $r_{i}$ and $r_{j}$ as the radii of a sphere enclosing the respective whole ice crystal. The larger the effective collision area, $\pi\left(r_{i}+r_{j}\right)^{2}$, and the relative sedimentation speed $\left|v_{\mathrm{t}, i}-v_{\mathrm{t}, j}\right|$, the more likely aggregation occurs. Note that $K_{i j}$ is symmetrical and vanishes for $v_{\mathrm{t}, i}=v_{\mathrm{t}, j}$.

Using the LPT approach, Eq. (32) is not directly applied in the LCM. Instead, the LPT enables a more direct representation of the aggregation process (right of Figure 5). We make use of the idea of the sweep-out process that underlies differential sedimentation and present an algorithm for aggregation between different SIP based on their individual trajectories. For computational efficiency, aggregation is only considered within a grid box, not across grid box boundaries. This may lead to an underestimation of the number of aggregation events.

1. Positions of the $N_{\mathrm{p}}$ SIPs are ordered according to their vertical coordinates in each grid box, facilitating the identification of aggregating particle pairs based on individual SIP trajectories from Eq. (22).

2. Starting from the uppermost $\operatorname{SIP} i$, all lower SIPs $j$ which collide during $\Delta t_{\mathrm{M}}$ are identified (Figure 5). Collisions occur if

$$
z_{i}-\left(v_{\mathrm{t}, i}+\tilde{u}_{i}\right) \delta t^{\prime}=z_{j}-\left(v_{t, j}+\tilde{u}_{j}\right) \delta t^{\prime},
$$

i.e. provided that

$$
\delta t^{\prime}=\frac{z_{i}-z_{j}}{\left(v_{\mathrm{t}, i}+\widetilde{u}_{i}\right)-\left(v_{\mathrm{t}, j}+\widetilde{u}_{j}\right)}<\Delta t_{\mathrm{M}}
$$

holds, where $\tilde{u}$ denote the turbulent velocity fluctuations superimposed on the terminal fall velocities $v_{\mathrm{t}}$.

3. For each SIP $j$ satisfying Eq. (35), we check if the faster-sedimenting SIP $i$ collects a real ice crystal contained in SIP $j$ during its passage. To accomplish this, we calculate the probability, $\Omega_{i}$, for the trajectory of a real ice crystal in SIP $i$ to intersect the effective collision areas surrounding the $\mathcal{N}_{j}$ real ice crystals represented by SIP $j$ :

$$
\Omega_{i}=E_{\mathrm{agg}} \frac{\mathcal{N}_{j} \pi\left(r_{i}+r_{j}\right)^{2}}{\Delta x \Delta y} .
$$

Here, we distribute the $\mathcal{N}_{j}$ real ice crystals homogeneously and without overlap across the grid box area, $\Delta x \Delta y$. As in the geometric sweep-out kernel, the use of $\pi\left(r_{i}+r_{j}\right)^{2}$ as an effective collision area gives an upper limit to simulate possible collisions for non-spherical ice crystals. This may overestimate the collision efficiency. In our explicit aggregation model, $E_{\text {agg }}$ modifies this probability for hydrodynamical effects, and for the sticking efficiency (section 4).

4. An aggregation event is realised when $\xi \leq \Omega_{i}$, with $\xi$ being a random number uniformly distributed in the interval $[0,1]$. Because the SIPs usually carry different numbers of real ice crystals, the maximum number of aggregating crystals is determined by the lower value. Suppose $\mathcal{N}_{i}>\mathcal{N}_{i}$, then all real ice crystals from $j$ aggregate with those from $i$ increasing each real ice crystal mass $m_{j}$ by $m_{i}$; the remaining ones stay in SIP $i$ and do not aggregate:

$$
\begin{aligned}
& \mathcal{N}_{i} \rightarrow \mathcal{N}_{i}-\mathcal{N}_{j} ; \quad m_{i} \rightarrow m_{i}, \\
& \mathcal{N}_{j} \rightarrow \mathcal{N}_{j} ; \quad m_{j} \rightarrow m_{j}+m_{i} .
\end{aligned}
$$

The advantage of the algorithm is that one can track the SIP properties properly, because the total mass of two ice crystals is conserved after aggregation. However, the probability $\Omega_{i}$ turns out to be rather low in cirrus clouds; if the number of SIPs in a grid box was too low, this would result in only few aggregation events, possibly underestimating the number of these events occurring in nature.

We set $E_{\text {agg }}$ constant in the LCM and vary its value in sensitivity studies because of the above-mentioned lack of a physical model for the hydrodynamical and microphysical parts affecting $E_{\text {agg. }}$. It may be replaced by a more realistic function of temperature, supersaturation, habit, size, or other variables, if appropriate theoretical models become available.

We validate the aggregation component in the LCM (section 5), an exercise which is considerably more challenging. An attempt to validate the full EULAGLCM model system by means of analysing regional field measurements of a cirrus cloud system is the subject of another study (Sölch and Kärcher, 2010).

\section{Validation of the aggregation algorithm}

We apply the aggregation algorithm presented in section 4 to an idealized case of a stratiform cirrus. We check whether 
the EULAG-LCM is capable of matching the physics of the aggregation process in cirrus by making use of a self-similar scaling relation that is based on the assumption of a constant ice mass flux density.

For a meaningful validation of aggregation under this assumption, we need to minimize the influence of other processes such as ice formation, depositional growth, atmospheric turbulence, radiative heating or cooling, and cloud inhomogenities, in an idealized simulation set-up; otherwise it would be unclear how well the analytical scaling, which has been verified by aircraft measurements (Field and Heymsfield, 2003), can be reproduced.

\subsection{Scaling of the ice particle size distribution}

Laboratory studies and numerical simulations of colloidal systems (Meakin, 1992) show that the the large size end of the PSD in many cirrus clouds, which is basically controlled by aggregation, can be scaled by self-similar distributions of the form (Field and Heymsfield, 2003)

$$
n(D, t)=\left\{D_{1}(t)\right\}^{-\Theta} g\left[\frac{D}{D_{1}(t)}\right],
$$

where $n(D, t)$ is the PSD at time $t, D_{1}$ is a characteristic, time-dependent (mean) maximum ice crystal dimension, $\Theta$ is a scaling exponent, and $g$ is a function depending only on the similarity variable $D / D_{1}$. Equation (39) states that the PSD tails for large ice crystals $(D>700 \mu \mathrm{m})$, obtained at different times, collapse onto a single curve $g$, if the size distributions are scaled by $D_{1}(t)$.

The scaling exponent, $\Theta$, can be found assuming conservation of the ice mass flux density, $\Phi$ (Field and Heymsfield, 2003):

$$
\Phi=\int_{0}^{\infty} n(D, t) m(D) v_{\mathrm{t}}(D) \mathrm{d} D .
$$

Approximating the true PSD tail above a few hundred microns by $n(D, t)=n_{0}(t) \exp \{-\lambda(t) D\}, \lambda=1 / D_{1}$, a welldefined relationship between the two parameters $n_{0}$ and $\lambda$ has been derived (Lo and Passarelli, 1982; Field, 1999):

$$
\mathrm{d}\left(\ln n_{0}\right)=\mathrm{d}(\ln \Phi)+\Theta \mathrm{d}(\ln \lambda) .
$$

For constant $\Phi$, Eq. (41) yields the scaling exponent $\Theta$ once the relationship $n_{0}(\lambda)$ is known. If the physics of the aggregation process are well represented by the LCM aggregation algorithm, the simulated PSD tails should roughly follow an exponential decay and should obey the scaling relation Eq. (41), inasmuch as the simulation conditions allow for $\Phi=$ constant.

\subsection{Idealized simulation set-up}

The model domain represents a $2 \mathrm{D}$ cross-section of the atmosphere, ranging vertically between $5 \mathrm{~km}$ and $10 \mathrm{~km}$, with a horizontal extension of $4 \mathrm{~km}$. Periodic lateral boundary conditions are applied and a grid spacing of $\Delta x=30 \mathrm{~m}$ and $\Delta z=20 \mathrm{~m}$ is used. In the interior of the stably stratified domain, a Brunt-Väisälä frequency of $N=0.01 \mathrm{~s}^{-1}$ and a vertical wind shear of $2 \mathrm{~s}^{-1}$ are assumed. To focus on the aggregation process, ice formation and radiative transfer are turned off.

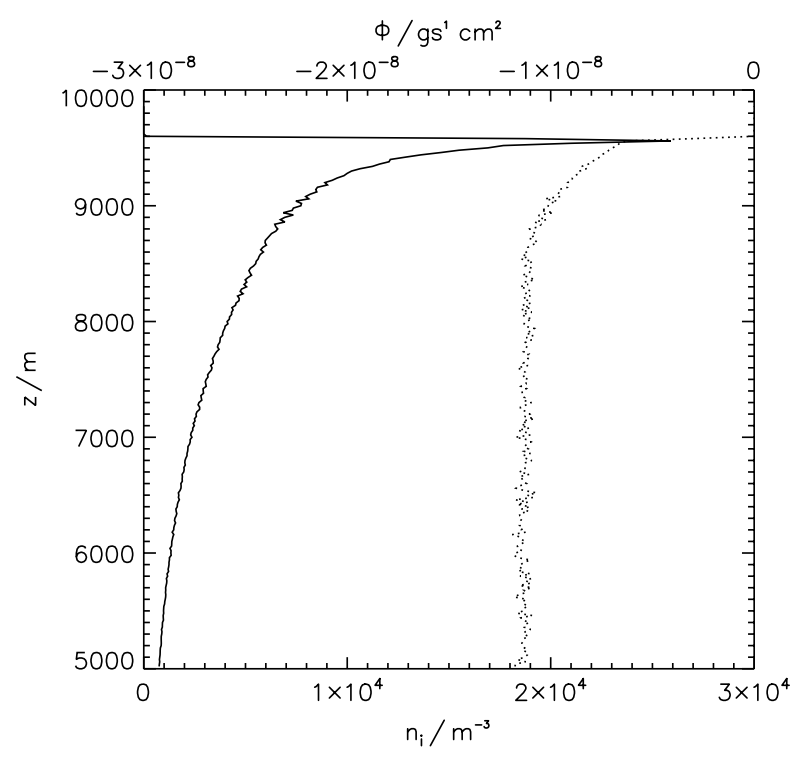

Figure 6. Horizontally averaged values of the ice crystal number concentration $n_{i}$ (solid line) and ice mass flux density $\Phi$ (dots) in the idealized simulation. Averages are performed in the fully developed cloud.

The simulation area is divided into two parts in the vertical, the growth region and the aggregation region. The depositional growth region is located in the upper part of the domain between 8600 and $10000 \mathrm{~m}$. Temperature and moisture profiles are chosen such that ice saturation ratio $S_{\mathrm{i}}$ increases from 1 to 1.2 , and $T$ decreases from 235 to $230 \mathrm{~K}$, with $p$ decreasing from 350 to $300 \mathrm{hPa}$. Latent heat release and water vapour depletion due to depositional growth is excluded. In the aggregation region below $8600 \mathrm{~m}$, we assume ice-saturated conditions to shut off depositional growth. Here, $T$ and $p$ range between 261 and $235 \mathrm{~K}$ and 560 and $350 \mathrm{hPa}$, respectively. The ice crystals fall out of the model domain below $5000 \mathrm{~m}$ without sublimating.

SIPs are continuously injected in a layer located at $9600 \mathrm{~m}$, resulting in peak ice crystal concentrations of $\sim 0.025 \mathrm{~cm}^{-3}$, typical for synoptically generated cirrus clouds with updraught speeds of a few centimetres per second (Lin, et al., 2005). A spread in particle dimensions and resulting sedimentation velocities is required for aggregation to occur. In natural cirrus, this spread is caused by different nucleation times and growth rates of individual ice crystals, arising from moisture and temperature fluctuations induced by turbulent motions in dynamically active, cirrusgenerating cells. Without these fluctuations, ice aggregation is unlikely to occur, because most of the newly injected SIPs are not able to catch up with those that have already grown and fallen to lower levels. To mimic the natural sources of variability responsible for the spread in particle properties, we superimpose an ambient turbulence field (mean eddy dissipation rate $6 \times 10^{-6} \mathrm{~m}^{2} \mathrm{~s}^{-2}$ in clear air) onto the model domain, generated with separate 3D EULAG simulations, which creates more variability in the wind and moisture fields. Some turbulence is generated by the model itself by shear and buoyancy forces. Further variability is created by assigning random initial sizes to the real ice crystals in the range $0.5-10 \mu \mathrm{m}$. The resulting variance in ice crystal properties and sedimentation velocities ensures that a large number of aggregation events occur in the simulation. Overall, our idealized set-up results in a constant ice mass flux density $\left(\Phi=10^{-8} \mathrm{~g} \mathrm{~s}^{-1} \mathrm{~cm}^{-2}\right)$ in the aggregation region of the fully developed cloud (cf. Figure 6), as required for 


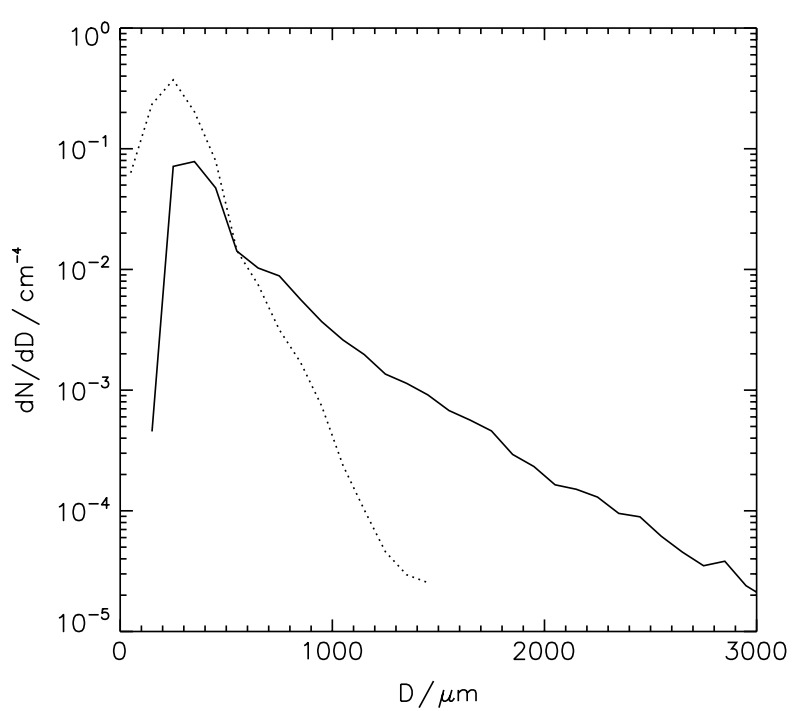

Figure 7. Ice crystal size distributions averaged over the growth region (dots) and aggregation region (solid line) in the fully developed cloud.

a proper validation (section (5.1)). For the aggregation efficiency, we prescribe a constant value $E_{\text {agg }}=1$. We set all time steps equal to $1 \mathrm{~s}$ and assume bullet rosette and aggregate habits for non-aggregated and aggregated ice crystals, respectively (Table AII). These habits are frequently observed in midlatitude cirrus (Field and Heymsfield, 2003).

\subsection{Simulation results: Idealized experiment}

In Figure 6, we show the horizontal averages of the $n_{\mathrm{i}}$ profile in the mature stage of the cloud evolution. In the nucleation layer, a peak ice crystal number concentration of $0.025 \mathrm{~cm}^{-3}$ is simulated, steadily decreasing towards the bottom of the domain $(5000 \mathrm{~m})$. In the idealized set-up, the ice mass flux density $\Phi$ is, as intended, spatially and temporally nearly constant in the aggregation region below $8600 \mathrm{~m}$.

Figure 7 displays the domain-averaged PSDs from the EULAG-LCM in the growth and aggregation region. The PSD in the aggregation zone exhibits a bimodal structure. The small size mode stems from the nucleation and depositional growth phase. The large size mode exhibits an exponential tail caused by the aggregation process. The PSD in the growth zone shows a much weaker, if any, aggregation signature. Interestingly, the PSD in the aggregation zone, and to some extend the PSD in the growth region, exhibits a 'shoulder shape', i.e. a concave deviation from the exponential form at $D=500 \mu \mathrm{m}$ (solid curve), similar to observations (Field, et al., 2005). This feature may be linked to the different growth mechanisms affecting the exponential tail (aggregation) and non-aggregated particles in the growth zone (deposition). Both simulated features, $\Phi=$ constant and $n(D>700 \mu \mathrm{m}) \propto \exp (-\lambda D)$, are present in the aggregation zone, ensuring that Eqs (39) and (41) may be applied to represent and scale the large size tails of the simulated PSDs.

Consequently, we apply the scaling relation Eq. (39) to validate the LCM aggregation algorithm. The relation postulates that the exponential tail of single PSDs, when solely affected by aggregation, should collapse onto a single function with constant scaling coefficient, $\Theta$, if scaled properly. To extract these PSDs, we picked only samples from the aggregation region supporting $\Phi=$ constant. Each
PSD displayed in Figure 8(a) is taken at subsequent time intervals, starting from the first height, $H_{1}$, and probing lower layers with height (integer $k$ )

$$
H_{k}=H_{1}-\bar{v}_{\mathrm{t}} k \Delta t
$$

assuming a constant average sedimentation velocity, $\bar{v}_{\mathrm{t}}=$ $1 \mathrm{~m} \mathrm{~s}^{-1}$, approximately following the population of the sedimenting and aggregating ice crystals.

The next step consists of fitting exponential functions to the large size tails of the simulated PSDs (Figure 8(b)) and deducing the associated scaling exponent, $\Theta$, from Eq. (41). The resulting $\Theta$ values are displayed in Figure 9.

In the idealized simulation, $\log n_{0}$ is related to $\log \lambda$ in an approximate linear fashion with slope $\Theta=3.72$ (Figure 9). This fact is strong evidence (Mitchell, et al., 2006) that aggregation is being treated correctly in the LCM. Lo and Passarelli (1982) pointed out that straight lines in $\lambda-n_{0}$ space represent a constant moment of an exponential distribution, i.e. ice mass flux density. Ideal homogeneous, steady-state, aggregating-only clouds would have $\lambda-n_{0}$ trajectories that followed these lines. For measurements in midlatitude cirrus, Mitchell (1988) find a slope of 2.1 and Field and Heymsfield (2003) of 3.9. The latter authors provide a relationship between $\Theta$ and the power law coefficients $\beta$ for mass and $b$ for the sedimentation velocity $\left(v_{\mathrm{t}, i}=a D_{i}^{b}\right)$ based on Eq. (40):

$$
\Theta=\beta+b+1 \text {. }
$$

For the relationships used in the EULAG-LCM, this yields $\Theta \approx 2.04+0.5+1=3.54$, in good agreement with the simulated $\Theta$ value of 3.72 (Figure 9). Note that our modelled sedimentation velocities do not follow a unique power law as required to use Eq. (43); the value used for $b$ is an estimate obtained by fitting power laws of the form $v_{\mathrm{t}, i}=a D_{i}^{b}$ to the simulated sedimentation velocities $v_{\mathrm{t}, i}$ (Appendix 6) for crystals $D>700 \mu \mathrm{m}$. A value of $b=0.5$ results from averaging the individual exponents, which are obtained for the different particle habits in the simulations.

Figure 8(c) and (d) show the rescaled PSDs. Together, Figures 8 and 9 demonstrate that the LCM algorithm is capable of adequately simulating the physics of aggregation driven by differential sedimentation, at least for nonconvective cirrus.

\section{Conclusion and outlook}

We have introduced a novel large-eddy simulation model for cirrus clouds with explicit aerosol and ice microphysics, the DLR EULAG-LCM. The cloud module LCM of the EULAG LES model uses a Eulerian approach to aerosol microphysics and Lagrangian tracking of simulation ice particles. Aerosol and ice phase are coupled through a number of homogeneous and heterogeneous ice formation processes to study aerosol-induced modification of cirrus. A process-oriented algorithm has been developed for ice aggregation due to differential sedimentation based on the trajectories and terminal fall speeds of individual ice particles. Results of the LCM have been compared to parcel model studies and analytical solutions in idealized 2D simulations. These comparisons have demonstrated that all core microphysical processes are well represented in the model system.

We have emphasised that the LCM is very well suited to perform detailed comparisons with field studies of cirrus 
(a)

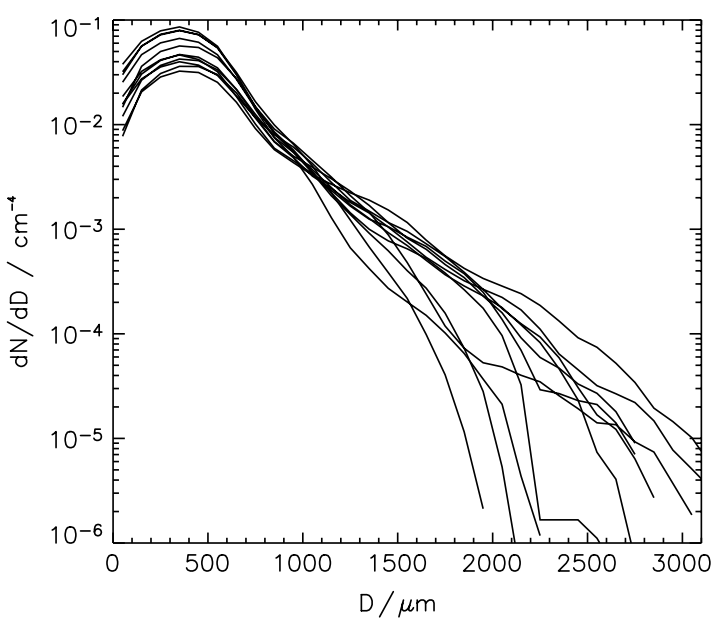

(c)

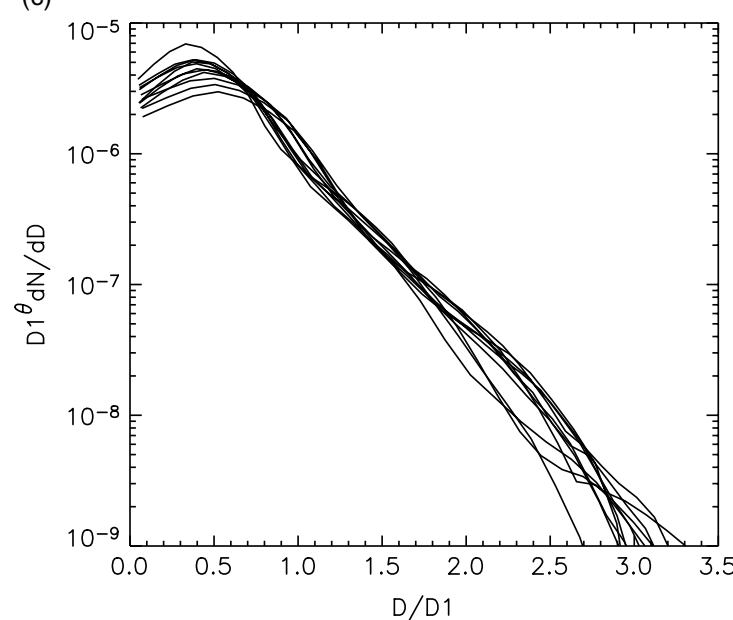

(b)

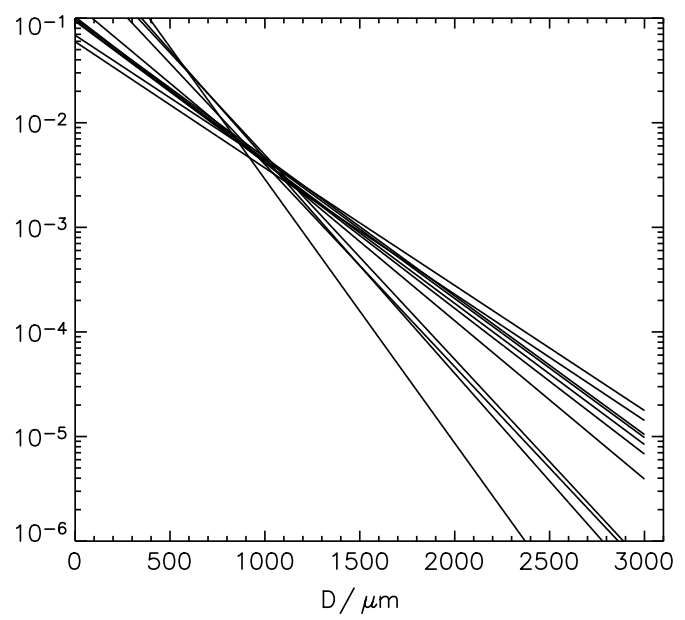

(d)

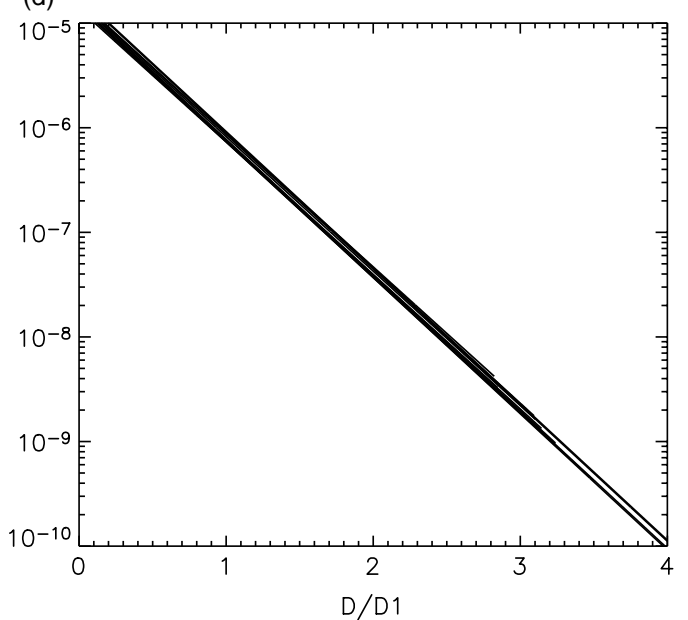

Figure 8. (a) Simulated ice crystal size distributions and (b) fitted $(D>700 \mu \mathrm{m})$ exponential functions $n_{0}(t) \exp \{-\lambda(t) D\}$, both for unscaled distributions. (c) and (d) are as (a) and (b), but for scaled distributions.

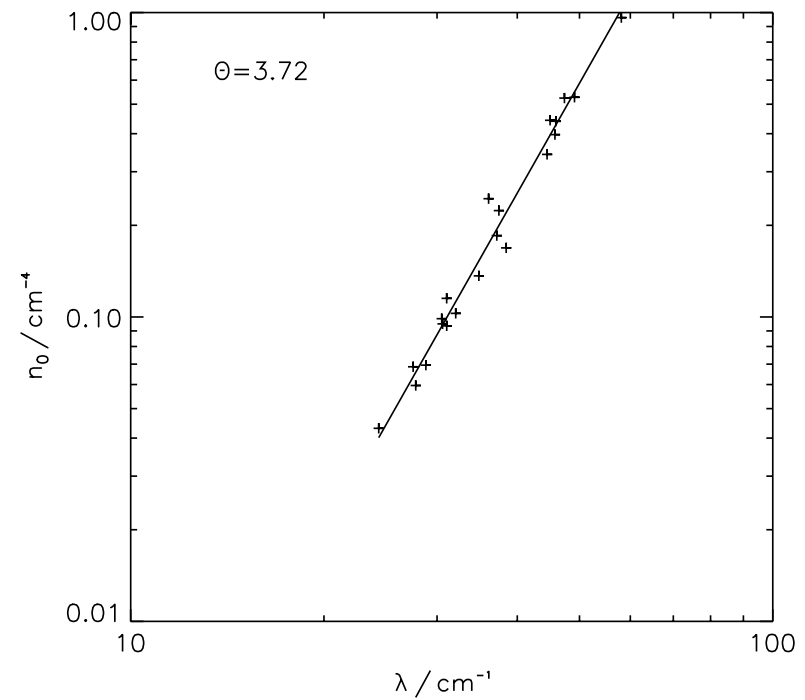

Figure 9. Information deduced from Figure 8, enabling the calculation of the scaling exponent, $\Theta$, in $\log \lambda-\log n_{0}$ space, using Eq. (41).

clouds. In the follow-on study, we apply the new model to a cirrus cloud system observed in detail within the US Atmospheric Radiation Measurement program (Sölch and Kärcher, 2010). We also plan to use the EULAG-LCM for basic studies of the moisture and condensate distributions in cirrus and persistent aircraft contrails (contrail cirrus) in order to aid the development of ice cloud parametrizations for use in global atmospheric models.

\section{Acknowledgements}

We are grateful to Andreas Dörnbrack and Claudia Emde for valuable assistance concerning EULAG and the radiation scheme, and to Graham Feingold and George Craig for fruitful discussions on cloud-resolving modelling. This work was funded, in part, by the European Integrated Project 'Stratosphere-Climate Links with Emphasis on the UTLS' (SCOUT-O3) and by the HGF Virtual Institute 'Aerosol-Cloud Interactions' (VI-ACI). It further contributes to the DLR project 'Climate-compatible air transport system' (CATS).

\section{Appendix}

\section{Ice crystal microphysical properties}

Table AI summarizes the symbols and the abbreviations used in this article. The following expressions for the 
Table AI. Summary of notation.

\begin{tabular}{|c|c|}
\hline$A_{\mathrm{c}}$ & Ice crystal cross-sectional area \\
\hline $\mathcal{A}_{i}$ & Aspect ratio of an ice crystal \\
\hline$a_{\mathrm{w}, l}$ & $\begin{array}{l}\text { Water activity of liquid aerosol particles } \\
\text { in size bin } l\end{array}$ \\
\hline$C_{\mathrm{D}}$ & Drag coefficient \\
\hline$C_{i}$ & Ice crystal capacitance \\
\hline $\mathrm{D}$ & Viscous force vector \\
\hline $\bar{D}$ & $\begin{array}{l}\text { Mean maximum dimension of an ice } \\
\text { crystal ensemble }\end{array}$ \\
\hline$D_{\text {ge }}$ & Generalized effective size (Fu, 1996) \\
\hline$D_{i}$ & Maximum dimension of an ice crystal \\
\hline$D_{\mathrm{v}}$ & Diffusion coefficient for water vapour in air \\
\hline$D_{1}$ & Characteristic mean length-scale \\
\hline$E_{\mathrm{agg}}$ & Aggregation efficiency \\
\hline$F_{\lambda}^{ \pm}$ & Radiative flux terms \\
\hline$f^{n}$ & Coriolis parameter \\
\hline$f_{\mathrm{v}}$ & Ventilation factor \\
\hline g & Gravitation vector \\
\hline$g$ & Similarity function (Eq. (39)) \\
\hline$H_{\mathrm{H}}$ & Heating rate due to radiation \\
\hline$H_{k}$ & Height layer $k$ \\
\hline$H_{\mathrm{R}}$ & $\begin{array}{l}\text { Heating rate due to latent heat from } \\
\text { water vapour deposition or sublimation }\end{array}$ \\
\hline$i, j, k$ & Subscripts denoting numerical index \\
\hline$j_{\mathrm{f}}$ & $\begin{array}{l}\text { Homogeneous freezing or heterogeneous } \\
\text { ice nucleation rate }\end{array}$ \\
\hline$J_{\mathrm{f}}$ & Homogeneous freezing rate coefficient \\
\hline$K_{i, j}$ & Collection kernel \\
\hline$K_{m}$ & Diffusion coefficient for momentum \\
\hline$k_{\mathrm{B}}$ & Boltzmann constant \\
\hline k & Unit vector in vertical direction \\
\hline$L_{\mathrm{s}}$ & Latent heat of sublimation \\
\hline$M$ & number of wavelength bands \\
\hline$m_{i}$ & Mass of an SIP \\
\hline$m_{n}$ & Number of SIPs created \\
\hline$m_{\mathrm{v}}$ & Mass of a water molecule \\
\hline$N_{\mathrm{A}}$ & Avogadro number \\
\hline $\mathcal{N}_{i}$ & $\begin{array}{l}\text { Number of real ice crystals represented } \\
\text { by an SIP }\end{array}$ \\
\hline$N_{\mathrm{p}}$ & $\begin{array}{l}\text { Number of simulation ice particles in a } \\
\text { grid box }\end{array}$ \\
\hline$N_{\text {SIP }}$ & Total number of simulation ice particles \\
\hline$n_{\mathrm{a}, l}$ & $\begin{array}{l}\text { Number concentration of liquid aerosol } \\
\text { particles in size bin } l\end{array}$ \\
\hline$n_{\mathrm{i}}$ & Number concentration of ice crystals \\
\hline$n_{\mathrm{p}}$ & Ice nuclei number concentration \\
\hline$n_{\mathrm{v}}$ & Gas phase number concentration of $\mathrm{H}_{2} \mathrm{O}$ \\
\hline$n_{\mathrm{v}, \mathrm{a}, l}$ & $\begin{array}{l}\text { Number concentration of } \mathrm{H}_{2} \mathrm{O} \text { molecules } \\
\text { in a liquid aerosol particle in size bin } l\end{array}$ \\
\hline$n_{\mathrm{v}, \mathrm{i}}$ & $\begin{array}{l}\text { Number concentration of } \mathrm{H}_{2} \mathrm{O} \text { molecules } \\
\text { in the ice phase }\end{array}$ \\
\hline$p$ & Air pressure \\
\hline$p^{\prime}$ & Pertubation pressure \\
\hline$p_{\mathrm{s}}$ & $\begin{array}{l}\text { Water saturation vapour pressure over a } \\
\text { flat pure water surface }\end{array}$ \\
\hline$p_{\mathrm{v}}$ & Water vapour partial pressure \\
\hline$p_{\mathrm{i}, s}^{\prime}$ & $\begin{array}{l}\text { Water saturation vapour pressure over a } \\
\text { curved ice surface }\end{array}$ \\
\hline
\end{tabular}

Table AI. (continued)

\begin{tabular}{|c|c|}
\hline$p_{\mathrm{a}, \mathrm{s}, l}^{\prime}$ & $\begin{array}{l}\text { Water saturation vapour pressure over a } \\
\text { liquid aerosol particle in size bin } l\end{array}$ \\
\hline$Q_{D}$ & Water vapour change by depositional growth \\
\hline$Q_{\mathrm{H}}$ & Latent heat source \\
\hline$Q_{\mathrm{N}}$ & Water vapour change by nucleation \\
\hline$Q_{R}$ & Radiative heat source \\
\hline$q_{\mathrm{i}}$ & Ice mass mixing ratio \\
\hline$q_{\mathrm{v}}$ & Water vapour mass mixing ratio \\
\hline$R_{\mathrm{d}}$ & Gas constant for dry air \\
\hline$R_{\mathrm{L}}$ & Lagrangian autocorrelation coefficient \\
\hline$R_{\mathrm{v}}$ & Gas constant for water vapour \\
\hline$r_{\mathrm{a}, l}$ & $\begin{array}{l}\text { Radius of a liquid aerosol particle } \\
\text { in size bin } l \text {. }\end{array}$ \\
\hline$r_{\mathrm{c}}$ & $\begin{array}{l}\text { Radius of an insoluble core in a liquid } \\
\text { aerosol particle }\end{array}$ \\
\hline$S_{\mathrm{cr}}$ & Heterogeneous ice nucleation threshold \\
\hline$S_{\mathrm{i}}$ & Ice saturation ratio \\
\hline$T$ & Air temperature \\
\hline $\mathbf{u}$ & Volume-averaged wind \\
\hline $\mathbf{u}^{\prime}$ & Volume-averaged perturbation wind \\
\hline$V_{\mathrm{b}}$ & Grid box volume \\
\hline $\mathbf{v}_{\mathrm{t}, i}$ & Terminal fall velocity of SIP $i$ \\
\hline $\mathbf{x}_{\mathrm{p}, i}$ & Position of SIP $i$ \\
\hline$\alpha, \beta, \gamma, \sigma$ & Coefficients in Eqs $(20),(21)$ \\
\hline$\beta_{\mathrm{v}, \mathrm{a}, l}$ & Size-dependent correction factor (Eq. (6)) \\
\hline$\Delta$ & Constant in Eq. (12) \\
\hline$\Delta a_{\mathrm{w}}$ & $\begin{array}{l}\text { Water activity shift in the shifted activity } \\
\text { method for heterogeneous ice nucleation }\end{array}$ \\
\hline$\Delta t$ & Dynamical time step \\
\hline$\Delta t_{\mathrm{M}}$ & Microphysical time step \\
\hline$\Delta t_{\mathrm{N}}$ & Time step during a nucleation event \\
\hline$\epsilon$ & $\left(R_{\mathrm{v}} / R_{\mathrm{d}}\right)-1$ \\
\hline$\zeta$ & IN nucleation fraction \\
\hline$\eta_{a}$ & Dynamic viscosity \\
\hline $\bar{\theta}$ & Anelastic potential temperature \\
\hline$\theta_{\mathrm{d}}$ & Density potential temperature \\
\hline$\theta_{\mathrm{e}}$ & Environmental potential temperature \\
\hline$\Theta$ & Scaling exponent (Eq. (39)) \\
\hline$\kappa_{\mathrm{d}}$ & Thermal conductivity of air \\
\hline$\xi$ & Random number $[0,1]$ \\
\hline$\Pi_{\mathrm{i}}$ & Ice crystal habit \\
\hline $\bar{\rho}$ & Anelastic density \\
\hline$\rho_{\mathrm{i}}$ & Ice mass density \\
\hline$\Phi$ & Ice mass flux density \\
\hline$\Omega_{i}$ & Ice crystal trajectory probability (Eq. (36)) \\
\hline
\end{tabular}

\section{Abbreviations}

IN Heterogeneous ice nucleus

IWC Ice water content

LCM Lagrangian cirrus module

LES Large-eddy simulation

LPT Lagrangian ice particle tracking

PSD Ice particle size distribution

RHI Relative humidity over ice

SIP Simulation ice particle

TKE Turbulent kinetic energy per unit mass 

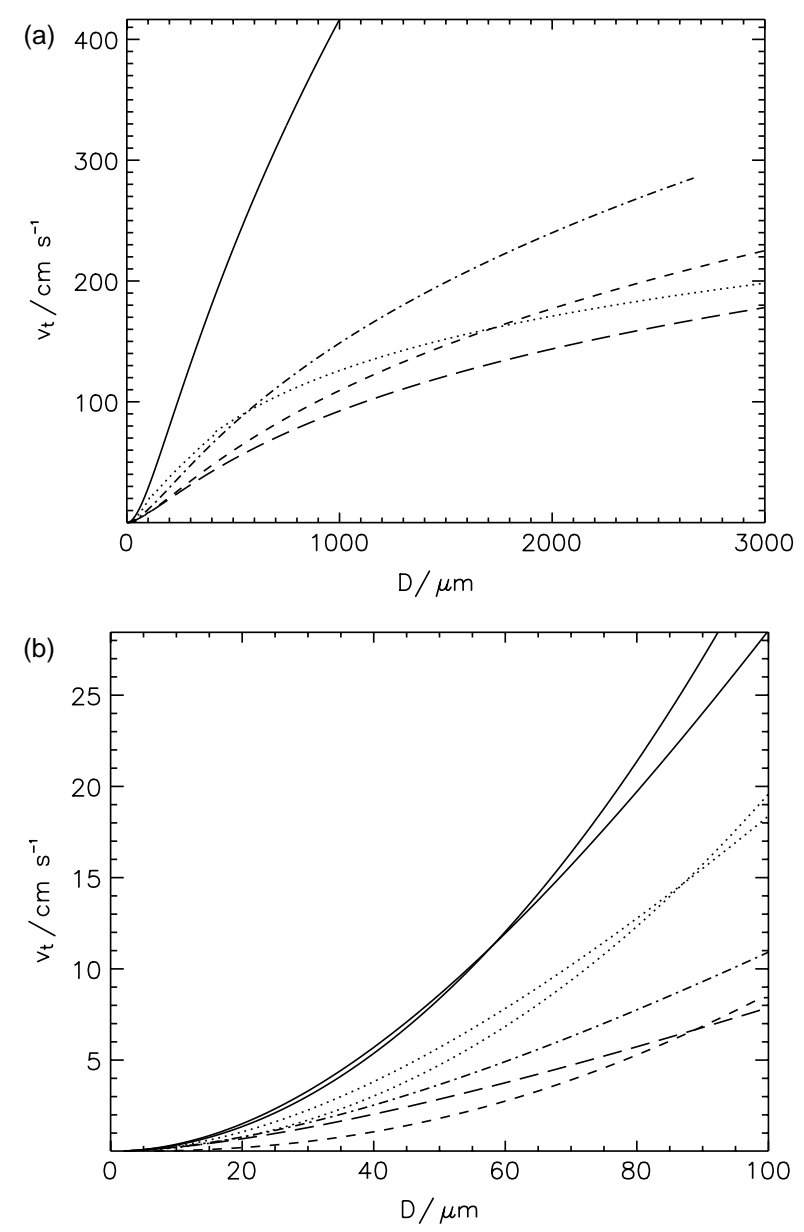

Figure A1. (a) Terminal fall velocities for $T=233 \mathrm{~K}$ and $p=350 \mathrm{hPa}$ and for different ice crystal habits as a function of maximum dimension $D$ according to Table AII. Spherical ice (solid curve), hexagonal columns (dotted), bullet rosettes (Mitchell, 1996) (dashed), bullet rosettes (Heymsfield, et al., 2002) (dash-dotted), and aggregates of bullet rosettes (Heymsfield, et al., 2002) (long dashed). (b) shows the same curves, focusing on particles with $D<100 \mu \mathrm{m}$. The additional thin solid and thin dotted curves displayed in (b) show $v_{\mathrm{t}}$ calculated according to Westbrook (2008) for spherical and hexagonal ice crystals, respectively.

microphysical properties of ice crystals are provided in c.g.s. units.

\section{A1. Terminal fall velocity}

Ice crystal terminal fall velocities, $v_{\mathrm{t}, i}$, are calculated via a relationship between Best number, $X$, and Reynolds number, Re, based on Mitchell and Heymsfield (2005). These authors improved surface roughness coefficients used in the theoretical treatment and introduced a correction term to the $R e-X$ relationship, improving the accuracy of their calculation, especially for aggregated ice crystals. Given the definitions

$$
\begin{aligned}
R e & =\frac{v_{\mathrm{t}, i} D_{i} \rho_{\mathrm{a}}}{\eta_{\mathrm{a}}}, \\
X & =C_{\mathrm{D}}(R e)^{2}=\frac{2 g \rho_{\mathrm{a}}}{\eta_{\mathrm{a}}^{2}} D_{i}^{2} \frac{m_{i}}{A_{i}},
\end{aligned}
$$

the relationship between the two numbers is

$$
R e=\frac{\delta_{0}^{2}}{4}\left\{\left(1+\frac{4 X^{1 / 2}}{\delta_{0}^{2} C_{0}^{1 / 2}}\right)^{1 / 2}-1\right\}^{2}-a_{0} X^{b_{0}}=a_{1} X^{b_{1}}
$$

With $R e$ from Eq. (A3), the terminal velocity is given by Eq. (A1). The power law coefficients in Eq. (A3) are given by

$$
\begin{aligned}
a_{1}= & \frac{C_{2}\left[\left(1+C_{1} X^{1 / 2}\right)^{1 / 2}-1\right]^{2}-a_{0} X^{b_{0}}}{X^{b_{1}}}, \\
b_{1}= & \frac{C_{1} X^{1 / 2}}{2\left[\left(1+C_{1} X^{1 / 2}\right)^{1 / 2}-1\right]\left(1+C_{1} X^{1 / 2}\right)^{1 / 2}} \\
& -\frac{a_{0} b_{0} X^{b_{0}}}{C_{2}\left[\left(1+C_{1} X^{1 / 2}\right)^{1 / 2}-1\right]^{2}} .
\end{aligned}
$$

The surface roughness is best described using $\delta_{0}=5.83$ and $C_{0}=0.6$ (Mitchell and Heymsfield, 2005). The other coefficients are $a_{0}=1.7 \times 10^{-3}, b_{0}=0.8, C_{1}=4 /\left(\delta_{0}^{2} C_{0}^{1 / 2}\right)$ and $C_{2}=\delta_{0}^{2} / 4$.

The accuracy of this approach depends primarily on the assumed mass- and area-dimensional power laws Eqs (20) and (21). Results for terminal fall velocities at $T=233 \mathrm{~K}$ and $p=350 \mathrm{hPa}$ using the power law relationships from Table AII are displayed in Figure A1. For small crystals $(D<100 \mu \mathrm{m})$, the calculated sedimentation velocities may deviate from the Stokes solution; Westbrook (2008) gives improved estimates for $v_{\mathrm{t}}$ for small ice crystals $(R e<1)$. We compare our sedimentation velocities to these improved estimates for spherical and hexagonal ice (thin solid and thin dotted lines in Figure A1, respectively) and find good agreement. For bullet rosettes and aggregates of bullet rosettes, Heymsfield, et al. (2002) fitted a relationship for the mass-to-area ratio, $m_{i} / A_{i}$, to aircraft measurements as a function of maximum dimension:

$$
\frac{m_{i}}{A_{i}}=0.0228 D_{i}^{0.59} \text {. }
$$

\section{A2. Capacitance}

The capacitance, $C_{i}$, for non-spherical ice crystals, used in the diffusional growth Eq. (14), is taken from Westbrook, et al. (2008), who directly simulated trajectories of a large number of diffusing water molecules, using a Monte Carlo approach.

The capacitance for hexagonal columns with length $D_{i}$ and aspect ratio $\mathcal{A}_{i}$ is

$$
C_{i}=\left\{0.58\left(1+0.95 \mathcal{A}_{i}^{0.75}\right)\right\} \frac{D_{i}}{2 \mathcal{A}_{i}}
$$

for bullet rosettes (6-rosettes) with maximum dimension $D_{i}$ and aspect ratio $\mathcal{A}_{i}$ of a single bullet is

$$
C_{i}=0.4 \mathcal{A}_{i}^{-0.25} D_{i}
$$

and for aggregates is

$$
C_{i}=0.25 D_{i}
$$

\section{A3. Ventilation coefficient}

The ventilation factor, $f_{\mathrm{v}}$, describes the increase of the depositional growth rate of ice crystals due to an enhanced water vapour flux arising from motion of the ice crystal 
Table AII. Ice crystal mass-diameter $\left(m_{i}=\alpha D_{i}^{\beta}\right)$ and projected area-diameter $\left(A_{i}=\gamma D_{i}^{\sigma}\right)$ relationships. The lowest section lists relationships for and images of ice crystals collected from in situ measurements. For spheres, a bulk ice mass density of $\rho_{\mathrm{i}}=0.92 \mathrm{~g} \mathrm{~m}^{-3}$ has been assumed.

\begin{tabular}{|c|c|c|c|c|c|}
\hline Habit & $\alpha$ & $\beta$ & $\gamma$ & $\sigma$ & Reference \\
\hline Spheres & 0.4765 & 3 & 3.1416 & 2 & \\
\hline \multicolumn{6}{|l|}{ Hexagonal columns $(\mathrm{C} 1 \mathrm{e})$ : } \\
\hline $30 \mu \mathrm{m}<D_{i} \leq 100 \mu \mathrm{m}$ & 0.1677 & 2.91 & 0.684 & 2 & Mitchell (1996) \\
\hline $100 \mu \mathrm{m}<D_{i} \leq 300 \mu \mathrm{m}$ & 0.00166 & 1.91 & 0.0696 & 1.5 & Mitchell (1996) \\
\hline $300 \mu \mathrm{m}<D_{i}$ & 0.000907 & 1.74 & 0.0512 & 1.414 & Mitchell (1996) \\
\hline \multicolumn{6}{|l|}{ Bullet rosettes $(\mathrm{C} 2 \mathrm{a})$ : } \\
\hline$D_{i} \leq 100 \mu \mathrm{m}$ & 0.1 & 2.2997 & 0.0869 & 1.57 & Mitchell (1996) \\
\hline$D_{i}>100 \mu \mathrm{m}$ & 0.00308 & 2.26 & 0.0869 & 1.57 & Mitchell (1996) \\
\hline \multicolumn{6}{|l|}{$\begin{array}{l}\text { ARM IOP (March 2000): } \\
\text { Bullet rosettes (C2a): }\end{array}$} \\
\hline$m_{i}-D_{i}$ & 0.0138 & 2.54 & - & - & Heymsfield, et al. (2002) \\
\hline$A_{i}-D_{i}(5$ branches $)$ & - & - & 0.2148 & 1.7956 & Heymsfield, et al. (2002) \\
\hline \multicolumn{6}{|l|}{ Aggregates: } \\
\hline & 0.00183 & 2.04 & - & - & Heymsfield, et al. (2002) \\
\hline
\end{tabular}

relative to the surrounding air. We adopt the results presented in Liu, et al. (2003) based on Ji and Wang (1999) for hexagonal columns and Heymsfield (1975) for bullet rosettes:

$$
f_{\mathrm{v}}=1.0+c_{1} X+c_{2} X^{2}
$$

where

$$
X=S c^{1 / 3}(R e)^{1 / 2}
$$

and $S c=v / D_{\mathrm{v}}$ is the Schmidt number. The coefficients $c_{1}$ and $c_{2}$ are provided in Table AIII. Note that for hexagonal columns, Eq. (A10) is only valid for $R e<20$; for larger $R e$, $f_{\mathrm{v}}(R e=20)$ is used. Ice columns with $R e>20$ are typically larger than $300 \mu \mathrm{m}$ (Eq. (A1)) and are mostly present only in very low number concentrations. Therefore, the cut-off at large $R e$ is not problematic, as diffusional growth is of minor importance at such large sizes.

For spherical ice particles we follow the treatment of Hall and Pruppacher (1976):

$$
f_{\mathrm{v}}= \begin{cases}1.0+0.14 X^{2}, & X<1.0, \\ 0.86+0.28 X, & X \geq 1.0 .\end{cases}
$$

\section{A4. Diffusivity of water vapour in air}

The diffusion coefficient of $\mathrm{H}_{2} \mathrm{O}$ molecules in air is approximated by

$$
D_{\mathrm{v}}=0.211\left(\frac{1013.25}{p}\right)\left(\frac{T}{273.15}\right)^{1.94},
$$

for $T$ ranging from $233.15 \mathrm{~K}$ to $313.15 \mathrm{~K}$ (Pruppacher and Klett, 1997), and $p$ in mb. Ghosh, et al. (2007) proposed a more accurate expression based on a Lennard-Jones model without formal temperature range restriction. When comparing both expression in LES model runs at $T<$ 233.15 K, deviations have been found to be small, justifying the use of Eq. (A13) in cirrus conditions.
Table AIII. Ventilation factor coefficients for ice crystals for use in Eq. (A10).

\begin{tabular}{lcr}
\hline Habit & $c_{1}$ & \multicolumn{1}{c}{$c_{2}$} \\
\hline Columns $(R e<20)$ & 0.0309 & 0.1447 \\
Bullet rosettes & 0.3005 & -0.0022 \\
\hline
\end{tabular}

\section{A5. Gas kinetic correction for water vapour diffusivity}

A size-dependent correction factor, $\beta_{\mathrm{v}, i}$, accounts for the transition between the diffusion-limited $\left(r_{i} \gg \lambda_{\mathrm{v}}\right)$ and the free molecular $\left(r_{i} \ll \lambda_{\mathrm{V}}\right)$ growth regime (Kärcher, 2003),

$$
\frac{1}{\beta_{\mathrm{v}, i}}=\frac{r_{i}}{r_{i}+\lambda_{\mathrm{v}}}+\frac{4 D_{\mathrm{v}} C_{0}}{\alpha_{\mathrm{v}} v_{\mathrm{th}, \mathrm{v}} r_{i}},
$$

where $C_{0}=C_{i} / D, \lambda$ is the mean free path of $\mathrm{H}_{2} \mathrm{O}$ molecules in air (Pruppacher and Klett, 1997), and

$$
\lambda_{\mathrm{v}}=6.15 \times 10^{-6}\left(\frac{1013.25}{p}\right)\left(\frac{T}{273.15}\right) .
$$

For $r_{i}$, we simply use the radius of a volume equivalent sphere, as small $(<1-5 \mu \mathrm{m})$ ice crystals, for which the correction is important, are approximately spherical; $\alpha_{\mathrm{v}}$ is the deposition coefficient for $\mathrm{H}_{2} \mathrm{O}$ molecules impinging on the ice surface. We set $\alpha_{\mathrm{v}}=0.5$ in agreement with laboratory and field studies (Haag, et al., 2003b; Kärcher and Ström, 2003), but any other choice could easily be adopted.

\section{References}

Anderson GP, Clough SA, Kneizys FX, Chetwynd JH, Shettle EP. 1986. AFGL atmospheric constituent profiles $(0-120 \mathrm{~km})$. AFGL-TR-860110, Env. Research Paper 954. Air Force Geophys. Lab: Hanscom AFB, Mass, USA. 
Bacon NJ, Swanson BD, Baker MB, Davis EJ. 1998. Breakup of levitated frost particles. J. Geophys. Res. 103: 13763-13775.

Bailey M, Hallett J. 2004. Growth rates and habits of ice crystals between -20 and $-70^{\circ}$ C. J. Atmos. Sci. 61: 514-544.

Bailey MP, Hallett J. 2009. A comprehensive habit diagram for atmospheric ice crystals: Confirmation from the laboratory, AIRS II, and other field studies. J. Atmos. Sci. 66: 2888-2899.

Bankert RL, Mitrescu C, Miller SD, Wade RH. 2009. Comparison of GOES cloud classification algorithms employing explicit and implicit physics. J. Appl. Meteorol. 48: 1411-1421.

Cantrell W, Heymsfield A. 2005. Production of ice in tropospheric clouds: A review. Bull. Amer. Meteorol. Soc. 86: 795-807.

Chen T, Rossow WB, Zhang Y. 2000. Radiative effects of cloud-type variations. J. Climate 13: 264-286.

Chiruta M, Wang PK. 2005. The capacitance of solid and hollow hexagonal ice columns. Geophys. Res. Lett. 32: L05803, DOI: 10.1029/2004GL021771.

Comstock JM, D'Entremont R, De Slover D, Mace GG, Matrosov SY, McFarlane SA, Minnis P, Mitchell D, Sassen K, Shupe MD, Turner DD, Wang Z. 2007. An intercomparison of microphysical retrieval algorithms for upper-tropospheric ice clouds. Bull. Amer. Meteorol. Soc. 88: 191-204.

Cziczo DJ, DeMott PJ, Brooks SD, Prenni AJ, Thomson DS, Baumgardner D, Wilson JC, Kreidenweis SM, Murphy DM. 2004. Observations of organic species and atmospheric ice formation. Geophys. Res. Lett. 31: L12116, DOI: 10.1029/2004GL019822.

DeMott PJ, Rogers DC, Kreidenweis SM. 1997. The susceptibility of ice formation in upper tropospheric clouds to insoluble aerosol components. J. Geophys. Res. 102: 19575-19584.

DeMott PJ, Cziczo DJ, Prenni AJ, Murphy DM, Kreidenweis SM, Thomson DS, Borys R, Rogers DC. 2003. Measurements of the concentration and composition of nuclei for cirrus formation. Proc. Natl. Acad. Sci. USA 100: 14655-14660.

Emanuel KA. 1994. Atmospheric convection. Oxford University Press: Oxford, UK.

Field PR. 1999. Aircraft observations of ice crystal evolution in an altostratus cloud. J. Atmos. Sci. 56: 1925-1941.

Field PR, Heymsfield AJ. 2003. Aggregation and scaling of ice crystal size distributions. J. Atmos. Sci. 60: 544-560.

Field PR, Hogan RJ, Brown PRA, Illingworth AJ, Choularton TW, Cotton R. 2005. Parametrization of ice-particle size distributions for mid-latitude stratiform cloud. Q. J. R. Meteorol. Soc. 131: 1997-2017.

Field PR, Heymsfield AJ, Bansemer A. 2006. A test of ice self-collection kernels using aircraft data. J. Atmos. Sci. 63: 651-666.

Finlayson-Pitts BJ, Pitts JN Jr. 2000. Chemistry of the upper and lower atmosphere. Academic Press: San Diego and London.

Franklin CN, Vaillancourt PA, Yau MK. 2007. Statistics and parameterizations of the effect of turbulence on the geometric collision kernel of cloud droplets. J. Atmos. Sci. 64: 938-954.

Fu Q. 1996. An accurate parametrization of the solar radiative properties of cirrus clouds for climate models. J. Climate 9: 2058-2082.

Fu Q, Liou K-N. 1992. On the correlated k-distribution method for radiative transfer in nonhomogeneous atmospheres. J. Atmos. Sci. 49: 2139-2156.

Ghosh S, Dobbie S, Marsham J, Jonas PR. 2007. On the importance of the diffusional uptake of water vapour for the development and radiative properties of high-altitude clouds: A large-eddy model sensitivity study. Q. J. R. Meteorol. Soc. 133: 1731-1741.

Gierens K. 1992. The influence of radiation on the diffusional growth of ice crystals. Beitr. Phys. Atmos. 67: 181-193.

Grabowski WW, Smolarkiewicz PK. 2002. A multiscale anelastic model for meteorological research. Mon. Weather Rev. 130: 939-956.

$\mathrm{Gu} \mathrm{Y,} \mathrm{Liou} \mathrm{KN.} \mathrm{2000.} \mathrm{Interactions} \mathrm{of} \mathrm{radiation,} \mathrm{microphysics,} \mathrm{and}$ turbulence in the evolution of cirrus clouds. J. Atmos. Sci. 57: 2463-2479.

Haag W, Kärcher B, Schaefers S, Stetzer O, Möhler O, Schurath U, Krämer M, Schiller C. 2003a. Numerical simulations of homogeneous freezing processes in the aerosol chamber AIDA. Atmos. Chem. Phys. 3: $195-210$.

Haag W, Kärcher B, Ström J, Minikin A, Ovarlez J, Lohmann U, Stohl A. 2003 b. Freezing thresholds and cirrus cloud formation mechanisms inferred from in situ measurements of relative humidity. Atmos. Chem. Phys. 3: 1791-1806.

Hall WD, Pruppacher HR. 1976. The survival of ice particles falling from cirrus clouds in subsaturated air. J. Atmos. Sci. 33: 1995-2006.

Hallett J, Mossop SC. 1974. Production of secondary ice particles during the riming process. Nature 249: 26-28.
Heymsfield AJ. 1975. Cirrus uncinus generating cells and the evolution of cirriform clouds: Part III. J. Atmos. Sci. 32: 799-808.

Heymsfield AJ. 2007. On measurements of small ice particles in clouds. Geophys. Res. Lett. 34: L23812, DOI: 10.1029/2007GL030951.

Heymsfield AJ, Lewis S, Bansemer A, Iaquinta J, Miloshevich LM, Kajikawa M, Twohy C, Poellot MR. 2002. A general approach for deriving the properties of cirrus and stratiform ice cloud particles. J. Atmos. Sci. 59: 3-29.

Hobbs PV. 1965. The aggregation of ice particles in clouds and fogs at low temperatures. J. Atmos. Sci. 22: 296-300.

Hosler CL, Hallgren RE. 1960. The aggregation of small ice crystals. Discuss. Faraday Soc. 30: 200-207.

Jacobson MZ. 1999. Fundamentals of atmospheric modelling. Cambridge University Press: Cambridge, UK.

Jensen E, Pfister L. 2005. Implications of persistent ice supersaturation in cold cirrus for stratospheric water vapor. Geophys. Res. Lett. 32: L01808, DOI: 10.1029/2004GL021125.

Jensen EJ, Toon OB, Westphal DL, Kinne S, Heymsfield AJ. 1994. Microphysical modeling of cirrus: 1. Comparison with 1986 FIRE IFO measurements. J. Geophys. Res. 99: 421-442.

Jensen EJ, Lawson P, Baker B, Pilson B, Mo Q, Heymsfield AJ, Bansemer A, Bui TP, McGill M, Hlavka D, Heymsfield G, Platnick S, Arnold GT, Tanelli S. 2009. On the importance of small ice crystals in tropical anvil cirrus. Atmos. Chem. Phys. 9: 5519-5537.

Ji W, Wang PK. 1999. Ventilation coefficients for falling ice crystals in the atmosphere at low-intermediate Reynolds number. J. Atmos. Sci. 56: 829-836.

Kahn BH, Gettelman A, Fetzer EJ, Eldering A, Liang CK. 2009. Cloudy and clear-sky relative humidity in the upper troposphere observed by the A-train. J. Geophys. Res. 114: D00H02, DOI: 10.1029/2009JD011738.

Kärcher B. 2003. Simulating gas-aerosol-cirrus interactions: Processoriented microphysical model and applications. Atmos. Chem. Phys. 3: $1645-1664$.

Kärcher B. 2005. Supersaturation, dehydration, and denitrification in Arctic cirrus. Atmos. Chem. Phys. 5: 1757-1772.

Kärcher B, Burkhardt U. 2008. A cirrus cloud scheme for general circulation models. Q. J. R. Meteorol. Soc. 134: 1439-1461.

Kärcher B, Koop T. 2005. The role of organic aerosols in homogeneous ice formation. Atmos. Chem. Phys. 5: 703-714.

Kärcher B, Lohmann U. 2003. A parametrization of cirrus cloud formation: Heterogeneous freezing. J. Geophys. Res. 108: 4698, DOI: 10.1029/2002JD003220.

Kärcher B, Solomon S. 1999. On the composition and optical extinction of particles in the tropopause region. J. Geophys. Res. 104(D22): 27441-27459.

Kärcher B, Spichtinger P. 2009. Cloud-controlling factors of cirrus. Clouds in the Perturbed Climate System: Their Relationship to Energy Balance, Atmospheric Dynamics, and Precipitation. Strüngmann Forum Report, vol.2. Heintzenberg J, Charlson RJ. (eds.) MIT Press: Cambridge, Mass., USA.

Kärcher B, Ström J. 2003. The roles of dynamical variability and aerosols in cirrus cloud formation. Atmos. Chem. Phys. 3: 823-838.

Kärcher B, Abbatt JPD, Cox RA, Popp PJ, Voigt C. 2009a. Trapping of trace gases by growing ice surfaces including surface-saturated adsorption. J. Geophys. Res. 114: D13306, DOI: 10.1029/2009JD011857.

Kärcher B, Burkhardt U, Unterstrasser S, Minnis P. 2009b. Factors controlling contrail cirrus optical depth. Atmos. Chem. Phys. 9: 6229-6254.

Keith WD, Saunders CPR. 1989. The collection efficiency of a cylindrical target for ice crystals. Atmos. Res. 23: 83-95.

Khain AP, Sednev IL. 1995. Simulation of hydrometeor size spectra evolution by water-water, ice-water and ice-ice interactions. Atmos. Res. 36: 107-138.

Khain A, Pinsky M, Elperin T, Kleeorin N, Rogachevskii I, Kostinski A. 2007. Critical comments to results of investigations of drop collisions in turbulent clouds. Atmos. Res. 86: 1-20.

Khvorostyanov VI, Sassen K. 1998. Cirrus cloud simulation using explicit microphysics and radiation. Part I: Model description. J. Atmos. Sci. 55: $1808-1821$.

Knopf DA, Koop T. 2006. Heterogeneous nucleation of ice on surrogates of mineral dust. J. Geophys. Res. 111: D12201, DOI: 10.1029/2005JD006894.

Koop T, Luo BP, Tsias A, Peter T. 2000. Water activity as the determinant for homogeneous ice nucleation in aqueous solutions. Nature 406: $611-614$. 
Lasher-Trapp SG, Cooper WA, Blyth AM. 2005. Broadening of droplet size distributions from entrainment and mixing in a cumulus cloud. Q. J. R. Meteorol. Soc. 131: 195-220.

Lawson RP, O'Connor D, Zmarzly P, Weaver K, Baker B, Mo Q, Jonsson H. 2006. The 2D-S (stereo) probe: Design and preliminary tests of a new airborne, high-speed, high-resolution particle imaging probe. J. Atmos. Oceanic Technol. 23: 1462-1477.

Levkov L, Rockel B, Kapitza H, Raschke E. 1992. 3D mesoscale numerical studies of cirrus and stratus clouds by their time and space evolution. Beitr. Phys. Atmos. 65: 35-58.

Lin RF, Starr DO'C, DeMott PJ, Cotton R, Sassen K, Jensen E, Kärcher B, Liu X. 2002. Cirrus parcel model comparison project. Phase 1: The critical components to simulate cirrus initiation explicitly. J. Atmos. Sci. 59: 2305-2329.

Lin RF, Starr DO'C, Reichardt J, DeMott PJ. 2005. Nucleation in synoptically forced cirrostratus. J. Geophys. Res. 110: D08208, DOI 10.1029/2004JD005362.

Liu H, Wang PK, Schlesinger RE. 2003. A numerical study of cirrus clouds. Part I: Model description. J. Atmos. Sci. 60: 1075-1084.

Liou K-N. 1986. Influence of cirrus clouds on weather and climate processes: A global perspective. Mon. Weather Rev. 114: 1167-1199.

Liou K-N, Fu Q, Ackermann TP. 1988. A simple formulation of the deltafour-stream approximation for radiative transfer parametrizations. J. Atmos. Sci. 45: 1940-1947.

Lo KK, Passarelli Jr RE. 1982. Growth of snow in winter storms: An airborne observational study. J. Atmos. Sci. 39: 697-706.

Luo BP, Carslaw KS, Peter T, Clegg SL. 1995. Vapour pressures of $\mathrm{H}_{2} \mathrm{SO}_{4} / \mathrm{HNO}_{3} / \mathrm{HCl} / \mathrm{HBr} / \mathrm{H}_{2} \mathrm{O}$ solutions to low stratospheric temperatures. Geophys. Res. Lett. 22: 247-250.

Lynch DK, Sassen K, Starr DO'C, Stephens G. 2002. Cirrus. Oxford University Press: New York.

Meakin P. 1992. Aggregation kinetics. Phys. Scr. 45: 295-331.

Meyers MP, DeMott PJ, Cotton WR. 1992. New primary ice-nucleation parameterizations in an explicit cloud model. J. Appl. Meteorol. 31 $708-721$.

Mitchell DL. 1996. Use of mass- and area-dimensional power laws for determining precipitation particle terminal velocities. J. Atmos. Sci. 53: $1710-1723$.

Mitchell DL. 1988. Evolution of snow-size spectra in cyclonic storms. Part I: Snow growth by vapor deposition and aggregation. J. Atmos Sci. 45: 3431-3451.

Mitchell DL, Heymsfield AJ. 2005. Refinements in the treatment of ice particle terminal velocities, highlighting aggregates. J. Atmos. Sci. 62 $1637-1644$.

Mitchell DL, Huggins A, Grubisic V. 2006. A new snow growth model with application to radar precipitation estimates. Atmos. Res. 82 $2-18$.

Möhler O, Stetzer O, Schaefers S, Linke C, Schnaiter M, Tiede R, Saathoff H, Krämer M, Mangold A, Budz P, Zink P, Schreiner J Mauersberger K, Haag W, Kärcher B, Schurath U. 2003. Experimental investigation of homogeneous freezing of sulphuric acid particles in the aerosol chamber AIDA. Atmos. Chem. Phys. 3: 211-223.

Möhler O, Field PR, Connolly P, Benz S, Saathoff H, Schnaiter M, Wagner R, Cotton R, Krämer M, Mangold A, Heymsfield AJ. 2006 Efficiency of the deposition mode ice nucleation on mineral dust particles. Atmos. Chem. Phys. 6: 3007-3021.

Monier M, Wobrock W, Gayet J-F, Flossmann AI. 2006. Development of a detailed microphysics cirrus model tracking aerosol particles' histories for interpretation of the recent INCA campaign. J. Atmos. Sci. 63: 504-525.

Morrison H, Grabowski WW. 2008. A novel approach for representing ice microphysics in models: Description and tests using a kinematic framework. J. Atmos. Sci. 65: 1528-1548.

Murphy DM, Koop T. 2005. Review of the vapor pressure of ice and supercooled water for atmospheric applications. Q. J. R. Meteorol. Soc. 131: 1539-1565.

Murphy DM, Thomson DS, Mahoney MJ. 1998. In situ measurements of organics, meteoritic material, mercury, and other elements in aerosols at 5 to $19 \mathrm{~km}$. Science 282: 1664-1669.

Murray BJ, Wilson TW, Dobbie S, Cui Z, Al-Jumur SMRK, Möhler O, Schnaiter M, Wagner R, Benz S, Niemand M, Saathoff H, Ebert V, Wagner S, Kärcher B. 2010. Heterogeneous nucleation of ice particles on glassy aerosols under cirrus conditions. Nature Geosci. 3: 233-237.

Ovarlez J, Gayet J, Gierens K, Ström J, Ovarlez H, Auriol F, Busen R, Schumann U. 2002. Water vapour measurements inside cirrus clouds in Northern and Southern Hemispheres during INCA. Geophys. Res. Lett. 29: 1813, DOI: 10.1029/2001GL014440.
Pinsky M, Khain A, Krugliak H. 2008. Collisions of cloud droplets in a turbulent flow.Part V: Application of detailed tables of turbulent collision rate enhancement to simulation of droplet spectra evolution. J. Atmos. Sci. 65: 357-375.

Pruppacher HR, Klett JD. 1997. Microphysics of clouds and precipitation. Kluwer Academic Publishers: Dordrecht, The Netherlands.

Quante M, Starr DO'C. 2002. Dynamical process in cirrus clouds: A review of observational results. In Cirrus. Lynch DK, Sassen K, Starr DO'C, Stephens G. (eds.) Oxford University Press: New York.

Ramaswamy V, Detwiler A. 1986. Interdependence of radiation and micophysics in cirrus clouds. J. Atmos. Sci. 43: 2289-2301.

Rauber RM. 1987. Characteristics of cloud ice and precipitation during wintertime storms over the mountains of Northern Colorado. J. Climate Appl. Meteorol. 26: 488-524.

Richardson MS, DeMott PJ, Kreidenweis SM, Petters MD, Carrico CM. 2010. Observations of ice nucleation by ambient aerosol in the homogeneous freezing regime. Geophys. Res. Lett. 37: L04806, DOI: 10.1029/2009GL041912.

Schilling V, Siano S, Etling D. 1996. Dispersion of aircraft emissions due to wake vortices in stratified shear flows: A two-dimensional numerical study. J. Geophys. Res. 101: 20965-20974.

Schröder FP, Kärcher B, Fiebig M, Petzold A. 2002. Aerosol states in the free troposphere at northern midlatitudes. J. Geophys. Res. 107: 8126, DOI: $10.1029 / 2000 J D 000194$

Schumann U. 1991. Subgrid length-scales for large-eddy simulation of stratified turbulence. Theor. Comput. Fluid Dyn. 2: 279-290.

Seifert A, Beheng KD. 2006. A two-moment cloud microphysics parameterization for mixed-phase clouds. Part 1: Model description. Meteorol. Atmos. Phys. 92: 45-66.

Shaw RA. 2003. Particle-turbulence interactions in atmospheric clouds. Annu. Rev. Fluid Mech. 35: 183-227.

Shutts GJ, Gray MEB. 1994. A numerical modelling study of the geostrophic adjustment process following deep convection. Q. J. R. Meteorol. Soc. 120: 1145-1178.

Smolarkiewicz PK, Margolin L. 1998. MPDATA: A finite-difference solver for geophysical flows. J. Comput. Phys. 140: 459-480.

Smolarkiewicz P, Margolin L. 2005. On forward-in-time differencing for fluids: An Eulerian semi-Lagrangian non-hydrostatic model for stratified flows. Atmos.-Ocean 35: 127-152.

Sölch I, Kärcher B. 2010. Process-oriented large-eddy simulations of a midlatitude cirrus cloud system based on observations. Q. J. R. Meteorol. Soc. submitted.

Spichtinger P, Gierens KM. 2009. Modelling of cirrus clouds. Part 1a: Model description and validation. Atmos. Chem. Phys. 9: 685-706.

Starr DO'C, Cox SK. 1985. Cirrus clouds: Part I: A cirrus cloud model. J. Atmos. Sci. 42: 2663-2681.

Stephens GL. 1983. The influence of radiative transfer on the mass and heat budgets of ice crystals falling in the atmosphere. J. Atmos. Sci. 40: $1729-1739$.

Stephens GL, Kummerow CD. 2007. The remote sensing of clouds and precipitation from space: A review. J. Atmos. Sci. 64: 3742-3765.

Stevens B, Feingold G, Cotton WR, Walko RL. 1996. Elements of the microphysical structure of numerically simulated nonprecipitating stratocumulus. J. Atmos. Sci. 53: 980-1006.

Stoelinga MT, Locatelli JD, Woods CP. 2007. The occurence of 'irregular' ice particles in stratiform clouds. J. Atmos. Sci. 64: 2740-2750.

Wang Z, Sassen K. 2001. Cirrus cloud microphysical property retrieval using lidar and radar measurements. Part I: Algorithm description and comparison with in situ data. J. Appl. Meteorol. 41: 218-229.

Westbrook CD. 2008. The fall speeds of sub- $100 \mu \mathrm{m}$ ice crystals. Q. J. $R$. Meteorol. Soc. 134: 1243-1251.

Westbrook CD, Ball RC, Field PR, Heymsfield AJ. 2004. Theory of growth by differential sedimentation, with application to snowflake formation. Phys. Rev. E 70: 021403 1-021403-7.

Westbrook CD, Hogan RJ, Illingworth AJ. 2008. The capacitance of pristine ice crystals and aggregate snowflakes. J. Atmos. Sci. 65: 206-219.

Yang P, Wei H, Huang H, Baum BA, Hu YX, Kattawar GW, Mishchenko MI, Fu Q. 2005. Scattering and absorption property database for nonspherical ice particles in the near- through farinfrared spectral region. Appl. Opt. 44: 5512-5523.

Zobrist B, Marcolli C, Koop T, Luo BP, Murphy DM, Lohmann U, Zardini AA, Krieger UK, Corti T, Cziczo DJ, Fueglistaler S, Hudson PK, Thomson DS, Peter T. 2006. Oxalic acid as a heterogeneous ice nucleus in the upper troposphere and its indirect aerosol effect. Atmos. Chem. Phys. 6: 3115-3129. 